\title{
Surface Hybrid Nanocomposite Produced by Friction Stir Processing: Microstructural Evolution, Mechanical Properties and Tribological Behavior
}

\section{Saeed Ahmadifard}

Bu-Ali Sina University

Nasir Shahin

Bu-Ali Sina University

Mojtaba Vakili-azghandi ( $\square$ mvakili2@uwo.ca )

University of Gonabad

Shahab Kazemi

Bu-Ali Sina University

\section{Research Article}

Keywords: Surface hybrid nanocomposite, Ti3AIC2 MAX phase, Microstructure, Atomic force microscopy, Mechanical properties, Tribological behavior

Posted Date: March 11th, 2021

DOI: https://doi.org/10.21203/rs.3.rs-268339/v1

License: (9) This work is licensed under a Creative Commons Attribution 4.0 International License. Read Full License 


\section{Abstract}

This study investigates the effects of incorporating $\mathrm{Ti}_{3} \mathrm{AlC}_{2} \mathrm{MAX}$ phase into Al7075-T6 alloy by friction stir processing as well as adding $\mathrm{Al}_{2} \mathrm{O}_{3}$ nanoparticles to obtain a surface hybrid nanocomposite. These composites were successfully prepared by friction stir processing with a rotational speed of $1000 \mathrm{rpm}$ and a travel speed of $28 \mathrm{~mm} / \mathrm{min}$ after 3 passes. Optical, atomic force and scanning electron microscopy as well as microhardness, tensile and wear tests utilized to characterize the fabricated surface hybrid nanocomposites. Results showed that the maximum tensile strength and hardness value were achieved for $\mathrm{Al}-100 \% \mathrm{Al}_{2} \mathrm{O}_{3}$ composite due to more grain refinement and effective dispersion of nanoparticles. Due to its laminar structure, $\mathrm{Ti}_{3} \mathrm{AlC}_{2} \mathrm{MAX}$ phase enhanced better tribological characterization whereas $\mathrm{Al}_{2} \mathrm{O}_{3}$ nanoparticles cause better mechanical properties. Scanning electron microscopy tests revealed that the wear mechanism changes from adhesive for Al7075 alloy to adhesive-abrasive for the nanocomposite specimens.

\section{Introduction}

As low weight materials, aluminum and its alloys including Al7075 are being widely used as structural materials due to their low density, high strength, ductility, toughness, and fatigue resistance (1-3). Their surface properties such as wear resistance often determine the useful life of components for many applications. Poor wear resistance of aluminum alloys is a major limitation for many applications. A dispersed reinforcement in the surface in order to have a uniform layer as a surface composite is one solution (4). By using more than one reinforcement phase, it is possible to have a special group of composites called hybrid composites. By changing the type and amount of each reinforcement in the hybrid composites, their mechanical and tribological properties could be controlled, and several studies have dealt with this issue (5-10). Tribological properties are the surface-dependent characteristics of materials, which can be proposed to fabricate a hybrid composite locally on the surface of a matrix with high mechanical properties. When a solid lubricant and a hard ceramic phase are presented in a hybrid system, better tribological properties could be achieved in addition to mechanical properties. The solid lubricant improves tribological properties and is usually soft, but the hard particles enhance mechanical properties. These composites represent a lower friction coefficient due to the formation of a lubricative film on the wearing surface of the composite; and this will also reduce the frictional heat generation. This can result in lower power loss and better efficiency. In this regard, Srinivasu et al. (8) improved wear resistance of cast aluminum silicon alloy A356 by forming a surface composite with boron carbide and molybdenum disulfide powders. In another study, Mostafapour et al. (10) investigated the role of hybrid ratio on microstructural, mechanical and sliding wear properties of the Al5083/Graphite/ $/ \mathrm{Al}_{2} \mathrm{O}_{3}$ surface hybrid nanocomposite.

It is difficult to disperse reinforcements on metallic substrate by conventional surface treatments in order to produce surface metal matrix nanocomposite and to control its distribution (11-13). Friction stir processing (FSP) is a new solid-state processing technique for microstructural modification, and it is 
developed based on the principle of friction stir welding (FSW). A brief description of the composite fabrication by FSP can be found in literature (14). The processing at temperatures below melting point of substrate is favorable as unwanted interfacial reaction between reinforcement and matrix can be avoided $(14,15)$. A significant development in the microstructure has occurred during this process because of the severe plastic deformation and thermal exposure of material (16). The resulting microstructure is created in three primary zones: the heat affected zone (HAZ), the thermo-mechanically affected zone (TMAZ), and the stir zone (SZ). Because of severe plastic deformation, fine grains can be achieved in SZ (17). It is well known that the microstructure of the $\mathrm{SZ}$ consists of fine and equiaxed grains due to dynamic recrystallization $(18,19)$. FSP has proved to be successful in the adaptation of various properties such as mechanical properties (20-22), enhancing the machinability $(23)$, fatigue $(24,25)$, wear $(9,10,26,27)$ and corrosion resistance (7).

Recently, a class of ternary layered compounds, $M_{n+1} A X_{n}$ phases (MAX for short, where $n=1,2$ or 3 , $M$ is early transition metal, $A$ is an A-group element (mostly groups 13 and 14), and $X$ is $C$ or $N$ ), has attracted much attention. The reasons are the unique combination of both metal- and ceramic-like properties including high fracture toughness, high Young's moduli, high thermal and electrical conductivities, easy machinability, excellent thermal shock resistance, high damage tolerance, and microscale ductility (28, 29). Titanium aluminum carbide $\left(\mathrm{Ti}_{3} \mathrm{AlC}_{2}\right)$ is a member of this family that has recently been shown to possess an unusual combination of properties, combining the merits of both metals and ceramics. Like metals, $\mathrm{Ti}_{3} \mathrm{AlC}_{2}$ is thermally and electrically conductive, easy to be machined with conventional tools and resistant to thermal shock. Like ceramics, it has a high strength, a high melting point and thermal stability. Those properties make $\mathrm{Ti}_{3} \mathrm{AlC}_{2}$ useful in many fields; for example, it can be used as a hightemperature structural material as an alternative for expensive high-temperature alloys (30-33). These kinds of compounds could be used as solid lubricants in hybrid composites. To the best of our knowledge, there are few reports about using $\mathrm{Ti}_{3} \mathrm{AlC}_{2} \mathrm{MAX}$ phase to manufacture surface composite by FSP. Then, the objective of this study is to investigate the use of $\mathrm{Ti}_{3} \mathrm{AlC}_{2} \mathrm{MAX}$ phase as well as $\mathrm{Al}_{2} \mathrm{O}_{3}$ nanoparticles to produce Al7075- 6 6 / $\mathrm{Ti}_{3} \mathrm{AlC}_{2} / \mathrm{Al}_{2} \mathrm{O}_{3}$ surface hybrid nanocomposite by FSP. Microstructure analysis, hardness, tensile and wear resistance of the manufactured hybrid nanocomposites were employed to investigate the effect of size, shape and type of dispersed particles on the final properties.

\section{Materials And Experimental Procedures}

\subsection{Materials}

In this study, Al7075-T6 alloy plate with $6 \mathrm{~mm}$ thickness in annealed condition was used. The T6 designation indicates peak-aging to optimize precipitation hardening. The chemical composition is presented in Table 1. The sheet was cut as rectangular samples of $150 \times 50 \times 6 \mathrm{~mm}^{3}$. A set of holes of 2 $\mathrm{mm}$ diameter and $3 \mathrm{~mm}$ depth with $4 \mathrm{~mm}$ intervals was made in the middle of the work piece (Fig. 1) and the holes were then filled with several ratios of $\mathrm{Ti}_{3} \mathrm{AlC}_{2}$ and $\mathrm{Al}_{2} \mathrm{O}_{3}$ as reinforcement phases. $\mathrm{Al}_{2} \mathrm{O}_{3}$ 
nanoparticles were supplied by the TECNON S.L. Company with a purity of $99 \%$ having an average particle size of $80 \mathrm{~nm}$. Powder of $\mathrm{Ti}_{3} \mathrm{AlC}_{2} \mathrm{MAX}$ phases were mechanochemically synthesized by commercially available powders of $\mathrm{Ti}$ (particle size $<100 \mu \mathrm{m}, 99.7 \%$ purity), Al (particle size $<200 \mu \mathrm{m}$, $99.7 \%$ purity) and graphite $C$ (particle size $<200 \mu \mathrm{m}, 99.7 \%$ purity). The synthesis route was presented elsewhere (34). These powders were weighed in a mole ratio according to the non-stoichiometric composition of $\mathrm{Ti}_{3} \mathrm{AlC}_{2}$ with Ti:Al:C = 3:1.2:2. The 10 hours milled powders were heat treated at temperature of $1200^{\circ} \mathrm{C}$ at a rate of $10^{\circ} \mathrm{C} / \mathrm{min}$ in a tube furnace under $\mathrm{Ar}$ atmosphere, and then cooled down to ambient temperature in such atmosphere. Fig. 2 shows the SEM micrograph of the synthesized powder and its XRD spectrum, when the main phases of the as-synthesized powder consisted of $\mathrm{Ti}_{3} \mathrm{AlC}_{2}$ and TiC. Calculations performed to determine the amount of each phase using $\mathrm{X}$-ray diffraction patterns show that $78 \%$ of the powder is $\mathrm{Ti}_{3} \mathrm{AlC}_{2}$ and $22 \% \mathrm{TiC}$. $\mathrm{Ti}_{3} \mathrm{AlC}_{2}$ acted as the lubricant and $\mathrm{TiC}$ was a hard and useful material to enhance mechanical properties. The formula presented for calculating each of these two phases is given below $(35,36)$ :

$$
\mathrm{W}_{\mathrm{TC}}=\frac{\left(\frac{I_{T C}}{I_{T A C}}\right)}{1.8+\left(\frac{I_{T C}}{I_{T A C}}\right)} \times 100
$$

$$
\mathrm{W}_{\mathrm{TAC}}=\left(1-\mathrm{W}_{\mathrm{TC}}\right) \times 100
$$

In this equation, $\mathrm{W}_{\mathrm{TC}}$ and $\mathrm{W}_{\mathrm{TAC}}$ are the weight percentages of $\mathrm{TiC}$ and $\mathrm{Ti}_{3} \mathrm{AlC}_{2}$, respectively, while $\mathrm{I}_{\mathrm{TC}}$ and $\mathrm{I}_{\mathrm{TAC}}$ are the sum of the peak intensities of each $\mathrm{TiC}$ and $\mathrm{Ti}_{3} \mathrm{AlC}_{2}$, respectively.

\subsection{Processing}

Several factors such as FSP parameters, tool/pin geometry and its type as well as size and ratio of reinforcements affected the final properties. The hybrid ratio, which can be defined as the volume proportion of each reinforcement phase in hybrid composite divided by total reinforcement volume of the composite, is an important factor, which controls the participation extent of reinforcement phase in overall properties of hybrid composite. The volume fraction of reinforcements depends on the number and size of holes. These factors were identical for all samples so that the overall volume fraction of reinforcements was constant. However, several $\mathrm{MAX}$ to $\mathrm{Al}_{2} \mathrm{O}_{3}$ ratios of $100 \% \mathrm{Al}_{2} \mathrm{O}_{3}, 50 \% \mathrm{Al}_{2} \mathrm{O}_{3}+50 \%$ MAX and $100 \%$ MAX were chosen.

The tool was made of $\mathrm{H} 13$ tool steel hardened to $58 \mathrm{HRC}$. A shoulder of $20 \mathrm{~mm}$ diameter with a square pin dimensions of $6 * 6 \mathrm{~mm}$ and pin length of $4 \mathrm{~mm}$ was used for FSP. Fig. 3 shows the photograph of the square tool and its dimensions. All the experiments were carried out at room temperature. The FSP was performed by three passes and at tool rotational speeds of $1000 \mathrm{rpm}$ and travel speeds of $28 \mathrm{~mm} / \mathrm{min}$. The tilt angle of the rotating tool with respect to the z-axis of the milling machine was 3 degrees for all 
samples. These conditions were chosen by trial and error method to achieve defect-free FSP. All samples even FSPed BM were subjected to 3 passes of FSP with different rotating directions in each pass to obtain more homogeneous dispersion of the reinforcements. Fig. 4 shows the schematic process of composite fabrication by FSP method.

\subsection{Characterizations}

Microstructural observations were carried out by optical microscope (Union Versamet-2), field emission scanning electron microscope (FESEM, TSCAN, Czech Republic) equipped with an energy dispersive spectroscopy (EDS) and atomic force microscope (AFM, DME DS-90-50E). To reveal the microstructures, the samples were prepared according to the conventional metallography procedures and etched with Keller's reagent ( $1 \mathrm{ml} \mathrm{HF}, 1.5 \mathrm{ml} \mathrm{HCl}$ and $2.5 \mathrm{ml} \mathrm{HNO}_{3}$ in $95 \mathrm{ml}$ distilled water for $10 \mathrm{~s}$ ). In addition, grain size measurement was carried out by using an image analyzer.

Vickers microhardness of BM and treated surfaces were measured based on the ASTM-E384 using Buehler's equipment by applying a load of $200 \mathrm{~g}$ for 20 seconds. Tensile tests were carried out at the ambient temperature by a SANTAM 150 tensile machine with the strain rate of $1 \mathrm{~s}^{-1}$. The tensile test specimens were dimensionally designed based on the ASTM-E8 standard. Fig. 5 shows size and configuration of FSPed and tensile specimens.

The wear behavior of the surface composite layer was studied by using a pin on disk tribometer (Arca Sanat Arvin) in room temperature condition. Wear test specimens of $10 \mathrm{~mm}$ diameter were cut from the middle of the SZ of FSPed surface by electro-discharge machining method. The tests were conducted based on ASTM G99-04 standard. The counterpart discs were made of AISI D3 steel hardened to 58 HRC with the surface roughness $(R a)$ of $0.2 \mu \mathrm{m}$. The surface of each pin was polished on 1000 grit emery paper before testing. The wear test was conducted at a sliding velocity of $1 \mathrm{~m} / \mathrm{s}$, normal force of $20 \mathrm{~N}$ and

sliding distance of $500 \mathrm{~m}$. The samples were cleaned with acetone and weighed to an accuracy of $0.1 \mathrm{mg}$ by electronic weighing balance after every $50 \mathrm{~m}$ intervals. The applied load as well as the sliding speed was fixed so that the active wear mechanisms in similar conditions could be compared. The friction coefficient between the pin and disc was determined by measuring the frictional force using a stress sensor at the distance of $500 \mathrm{~m}$ without stopping the disc rotation at the same sliding velocity and normal force. The surface roughness $(\mathrm{Ra})$ was also measured after wear tests using a profilometer model Mitutoyo to calculate the total depths of wear tracks and total wear rates. Finally, the worn surfaces were examined by scanning electron microscope (SEM, JEOL JSM-840A).

\section{Results And Discussion}

\subsection{Characterization of Microstructure}

Fig. 6 shows the cross-section optical micrograph of FSPed sample after three passes. Three distinct zones in the micrograph including SZ, thermo-mechanically affected zone (TMAZ), and BM can be clearly observed. Heat transfer of aluminum alloys is too high to form a distinct heat affected zone (HAZ). 
During FSP, severe increase of temperature and high plastic deformation lead to the formation of a fine equiaxed microstructure in the $S Z(8,16,17,20)$. Dynamic recovery (DRV), geometric dynamic recrystallization (GDRX) and discontinuous dynamic recrystallization (DDRX) have been considered the main mechanisms for grain refinement during FSP $(19,37)$. The optical microscopy images shown in Fig. 7 indicate the variations in the grain refinement of the composites fabricated by $\mathrm{Al}_{2} \mathrm{O}_{3}, \mathrm{MAX}$ particles and their mixture. The presence of reinforcements as second phase promoted grain refinement. These hard particles prevent the grain growth of new recrystallized grains by several mechanisms called the pinning effect. With an increase in the passes of FSP, powder distribution became more homogeneous in the matrix, reduction of clustering of reinforcement particles occurred and the size of the grain was also reduced.

As shown in Fig. 7 and Table 2, the grain size was decreased slightly when MAX particles were introduced. A more definite decrease in the grain size was observed when $\mathrm{Al}_{2} \mathrm{O}_{3}$ particles was used as refinement and reinforcement instead. As be seen, an average grain size of $4.6 \mu \mathrm{m}$ was obtained when both $\mathrm{MAX}$ and $\mathrm{Al}_{2} \mathrm{O}_{3}$ particles are used as refinement and reinforcement. The finer grain sizes observed in the SZ with particle addition might be due to the Zener pinning effect by the particles retarding the grain growth of the matrix. The effect of $\mathrm{Al}_{2} \mathrm{O}_{3}$ and $\mathrm{MAX}$ particles in pinning effect was different. It was described that during the recrystallization of metals with dispersed particles, the rate of grain growth can be defined using equation (3) (38).

$$
\frac{d R}{d t}=M\left(P-P_{z}\right)=M\left(\frac{\alpha \gamma_{b}}{R}-\frac{3 \gamma_{b} f_{v}}{2 r}\right)
$$

From the equation, $M$ is the boundary mobility, $F_{v}$ is the volume fraction, $P_{z}$ is the Zener pinning pressure, $P$ is the driving pressure from the curvature of the grain boundaries, $r$ is the radius of the pinning particles, $R$ is the radius of the grain, $Y_{b}$ is the boundary energy and $a$ is a small geometric constant. Therefore, when $\mathrm{P}=\mathrm{P}_{\mathrm{Z}}$, grain growth will stop.

$$
\frac{\alpha \gamma_{b}}{R}=\frac{3 \gamma_{b} f_{v}}{2 r}
$$

Thus, the Zener limiting grain size $(a=1)$ can be obtained when the radius of curvature $(R)$ and the mean grain radius $(D)$ are taken to be the same.

$$
D_{z}=\frac{f r}{3 f_{v}}
$$

However, with the addition of $\mathrm{Al}_{2} \mathrm{O}_{3}$ particles, a significant increase in the low angle boundary was observed in comparison to Aluminum containing MAX particles samples. This could be because $\mathrm{Al}_{2} \mathrm{O}_{3}$ particles are very small in size and it causes distortion and interference in the strain during 
thermomechanical process and dynamic recrystallization hence the resulting in lower angle boundary grains. Accordingly, as the MAX particles are smaller than the $\mathrm{Al}_{2} \mathrm{O}_{3}$ particles, the MAX particles are less effective in preventing grain growth phenomena during the thermomechanical treatment of FSP.

The significant decrease in grain sizes could be attributed to the incorporation of the reinforcement $\mathrm{Al}_{2} \mathrm{O}_{3}$ particles. The decrease in the grain size is less significant with the presence of MAX particles. The hardness of $\mathrm{Al}_{2} \mathrm{O}_{3}$ particles is high enough to prevent grain growth, while MAX particles have laminar structure, which leads to low contribution in pinning effect. This could be also because the MAX particles have broken down during the 3 passes of FSP. In this study, particle stimulated dynamic recrystallization is unlikely to have occurred as the employed particles sizes are less than $1 \mathrm{~mm}$.

Fig. 8 shows the FESEM micrograph of cross section of all three passes specimens except FSPed BM with EDS spectra for elemental composition. The micrograph clearly reveals that particle dispersion within the SZ is homogeneous and defect-free after FSP. It should be mentioned that no interfacial reaction in bonding of particles with surrounding matrix was observed. The EDS spectra of the specified areas in Fig. 8 (c) show that the particles in area B consists of titanium, aluminum and carbon while the particles in area A consists of aluminum and oxygen which shows the proper distribution of particles on the surface. Some agglomeration was detected for the sample without MAX phase because of the tendency of $\mathrm{Al}_{2} \mathrm{O}_{3}$ nanoparticles to agglomeration during FSP. This can be responsible for higher grain size of the sample and also has been observed in previous works (10). Similar results have been obtained for other composites.

It should be noted that one of the problems in the fabrication of the hybrid metal matrix composite by fusion processes or even by other ordinary solid-state processes such as power metallurgy (PM) was the agglomeration of the deferent reinforcements (11-13). In contrast to ordinary solid-state processes, agglomeration in the FSP is not considerable because the strong stirring action during FSP, which was considered one of the most prominent advantages of FSP, eliminated coarse clusters $(14,15)$.

The AFM microscopy images shown in Fig. 9 indicate the variations in the surface topography of the composites fabricated by $\mathrm{Al}_{2} \mathrm{O}_{3}$ and MAX particles. Fig. 9 (a), 9 (c) and 9 (e) show the 2D spectrums and Fig. 9 (b), 9 (d) and 9 (f) show the 3D images of the surface topography of $\mathrm{Al}_{2} \mathrm{O}_{3}$ and MAX surface composites. Fig. 9 (b), 9 (d) and 9 (f) show that the topographic data has been collected from a $10 \times 10$ $\mu \mathrm{m}$ surface of samples. According to Fig. 9 (a) and 9 (b), there is a maximum distance of $156.8 \mathrm{~nm}$ between the highest and deepest points on the surface of $\mathrm{Al}_{2} \mathrm{O}_{3}$ surface composite. Fig. 9 (c) and 9 (d) indicate that addition of $50 \% \mathrm{MAX}$ particles to $\mathrm{Al}_{2} \mathrm{O}_{3}$ particles, the surface roughness increases to 218.1 $\mathrm{nm}$ and Fig. 9 (e) and 9 (d) indicate a further increase in roughness value to 252.9. According to the literature the average grain size can be related to the roughness value in AFM images (39). On this basis, the micrographs of Fig. 9 indicate that the grain size is further refined by $\mathrm{Al}_{2} \mathrm{O}_{3}$ particles. As mentioned above $\mathrm{Al}_{2} \mathrm{O}_{3}$ particles are more effective than MAX particles to prevent grain growth during the FSP process. 


\subsection{Hardness}

Fig. 10 illustrates microhardness profiles of the composites along the thickness cross section for different states. The microhardness value of the base alloy was $88 \mathrm{Hv}$ and is unexpectedly decreased after FSP without reinforcement, which may be due to the growth of secondary phase particles (40). On the other hand the increase in hardness values was obviously in composites reinforced with $\mathrm{Al}_{2} \mathrm{O}_{3}$ and MAX particles separately or in combined form. The maximum hardness value was achieved for $100 \%$ $\mathrm{Al}_{2} \mathrm{O}_{3}$ of about $108 \mathrm{Hv}$, which was significant higher than that of base alloy. The increase in the microhardness value in the $\mathrm{SZ}$ was because of (i) a severe grain refinement during dynamic recrystallization and (ii) the particles, which are the harder phase and were distributed uniformly in the matrix. The latter cases of direct strengthening were imparted to the matrix by adding the strong and hard reinforcements, which act to hinder dislocation movement. TiC, presented in MAX phase and $\mathrm{Al}_{2} \mathrm{O}_{3}$, are hard particles that hinder dislocations and enhance the mechanical properties such as hardness. The former is due to the effect of microstructural modification in SZ, and it is proved that grain size refinement can enhance the hardness according to Hall-Petch relation. It is also believed that homogeneous distribution of nano-sized reinforcement results in pinning of dislocations and retarding grain growth $(10,21)$. Hall-Petch relationship states that the hardness is inversely proportional to the grain size. A direct correlation was seen in Table 2 and Fig. 10, which reveals that more refined structures cause higher hardness value. The increased hardness of FSPed surfaces has been reported by several studies $(41,42)$.

\subsection{Tensile properties}

Tensile properties of the BM and FSPed specimens are compared in Table 3 and Fig. 11. The tensile properties as well as elongation of the specimens are listed in Table 3. As seen, ultimate tensile strength (UTS) of all the FSPed specimens except the specimen without reinforcement is increased after FSP, and the maximum tensile strength of $351.12 \mathrm{MPa}$ is achieved for a specimen, which is reinforced by $100 \%$ of $\mathrm{Al}_{2} \mathrm{O}_{3}$ after three passes FSP. It should be noted that FSP without adding reinforcement phase results in decreasing about $50 \mathrm{MPa}$ in tensile strength (Table 3), Which may be due to the growth of secondary phase particles, whereas the presence of reinforcements enhances mechanical properties. In addition, the $\mathrm{Al}_{2} \mathrm{O}_{3}$ to $\mathrm{MAX}$ phase ratio has a remarkable effect on mechanical properties and microhardness. According to these properties, the highest microhardness and tensile strength are obtained for $100 \%$ $\mathrm{Al}_{2} \mathrm{O}_{3}$ specimen. Although all the FSPed specimens except the specimen without reinforcement improved tensile properties, a decrease in elongation was also observed for all the specimens. However, achieving optimum ratio leads to higher elongation in comparison to other FSPed specimens. According to Table 3 and Fig. 11, it is obvious that $\mathrm{Al}_{2} \mathrm{O}_{3}$ and $\mathrm{MAX}$ phase have similar effects on strengthening the aluminum alloy; however, it should be mentioned that $\mathrm{Al}_{2} \mathrm{O}_{3}$ is a little more effective while a hybrid effect on microhardness and mechanical properties for composites with two reinforcements is proved. This hybrid effect was found in the previous works $(9,43,44)$.

\subsection{Wear behaviors}




\subsubsection{Wear rate}

Figs. 12 and 13 show variations in weight loss and wear rate as a function of sliding distance for asreceived alloy and FSPed specimens, respectively. As shown in these figures, all composites except the specimen without reinforcement were worn less than base metal. FSPed specimen without reinforcement was worn more than BM and FSPed samples reinforced by particles. To improve the wear resistance of the aluminum alloy, $100 \%$ MAX phase specimen is clearly more efficient. According to the Archard's law of wear (45), volume loss is inversely proportional to the hardness of the surface composite. By increasing microhardness of the surface nanocomposite, metal removal during sliding wear decreases. Since maximum hardness was obtained for specimen FSPed with a ratio of $100 \% \mathrm{Al}_{2} \mathrm{O}_{3}$, it is in consistent with the fare wear rate obtained for this ratio. As mentioned above, the obtained improvement of wear resistance is related to higher hardness values because of microstructural evolutions and grain refinement during $\operatorname{FSP}(26,45)$.

In addition, the $100 \%$ MAX phase specimen composites causes the combined effect of individual reinforcement and then, exhibits lower wear rate compared to the as-received Al alloy and even FSPed surface composites. The presence of TiC particles act as load-bearing agents and $\mathrm{Ti}_{3} \mathrm{AlC}_{2}$ acts as a solid lubricant leading to improved wear resistance. The effect of solid lubricants such as graphite and $\mathrm{MoS}_{2}$ was reported for aluminum and magnesium alloys after $\mathrm{FSP}(8,10,43)$. In fact, using $\mathrm{Ti}_{3} \mathrm{AlC}_{2}$ particles as lubricants can result in lower wear rate. The composite consisting of these particles has a lamellar structure and exhibits lubrication characteristics (46).

\subsubsection{Coefficient of friction}

Fig. 13 shows the variation of the friction coefficient with sliding distance of $500 \mathrm{~m}$ for base metal, FSPed sample with and without reinforcement particles.

At the beginning of the test, in all the tested samples, similar to those reported in the literature $(47,48)$, the friction coefficient increased to a peak value followed by a lower steady state value. The initial increase in the friction coefficient may be due to the increase in the friction force needed to overcome the highly adhesive contact between the ball and the tested surface (48). The large fluctuations of the friction coefficient, which were observed in all the curves presented in Fig. 13 may be attributed to the periodical accumulation and elimination of wear debris on the worn track (47). Moreover, the repeated banding structure in the tool travelling direction resulting from the tool pitch, which was considered one of the significant characteristics of FSW/FSP (49), may contribute to this fluctuation.

The friction coefficients of the surface composites are presented in Table 3. Friction coefficient of BM is 0.663 and after FSP of the base metal, this value is Increased to 0.878. By adding MAX phase and $\mathrm{Al}_{2} \mathrm{O}_{3}$ particles, the friction coefficients of specimens are reduced. Table 3 describes that the specimen with $100 \%$ MAX has a better friction coefficient than other specimens. Decrease in grain size, increase in hardness and better dispersion of particles in the matrix improve wear properties of this sample. These 
mechanisms were reported for FSPed Al7075 with different reinforcement agents $(8,41,42)$. In addition, hard ceramic particles such as $\mathrm{Al}_{2} \mathrm{O}_{3}$ and $\mathrm{TiC}$ have a load-bearing behavior (27) and then cause notable reduction of direct load contact between the matrix and particles, thus the wear resistance of surface nanocomposite is improved.

Lower friction coefficient suggests that the mechanism of wear is chiefly abrasive because of the harder surface scratching over the softer surface. Again, for hybrid ratio of $100 \%$ MAX phase friction coefficient is minimum, which is consistent with microhardness and wear tests. According to Figs.11-13, FSP leads to an increase in wear resistance and a decrease in the friction coefficient. It obviously shows the hybrid effect of certain combination of $\mathrm{MAX}$ phase and $\mathrm{Al}_{2} \mathrm{O}_{3}$ particles on the wear and friction performance of the surface composites. Two reasons for the hybrid effects may include the hardening effect provided by $\mathrm{A}_{2} \mathrm{O}_{3}$ and $\mathrm{TiC}$ hard particles and the lubrication effect provided by $\mathrm{Ti}_{3} \mathrm{AlC}_{2}$.

\subsubsection{Worn surface analysis}

To examine the wear mechanism, surface morphology of the worn specimen and wear debris were analyzed. Fig. 15 shows SEM micrographs of worn surface and debris of BM and other FSPed specimens. Fig. 14 (b) shows pits and deep grooves which prove adhesive wear in wear surface morphology of FSPed base metal. It reveals that intensive material removal and plastic deformation has occurred (47). Wider and deeper grooves in worn surface of this specimen indicate that adhesive wear has happened. Presence of reinforcing particles in specimens FSPed with MAX phase and $\mathrm{Al}_{2} \mathrm{O}_{3}$ powders prevents adhesive wearing and drastic material removal. The debris particles in Fig. 10 (c) and (d) are related to oxidization and removal of base aluminum and segregation of reinforcement particles from surface composite layer during wear test. As it can be seen in Fig. 14 (e), it was observed that there were some parallel grooves in the smooth worn surface of the 100\% MAX composite. Piled up and partly broken materials at the edge of grooves are evidences indicating metal flow and crater as well as microcracks on the FSPed worn surfaces. The evidences indicating both adhesive and abrasive wear mechanisms in other samples have been observed. The metal removal rate during sliding is less in abrasive mode compared to the adhesive mode of wear. Therefore, it can be concluded that the asreceived BM and FSPed BM have adhesive wear mechanism, and surface nanocomposites have both adhesive and abrasive wear mechanisms. According to wear rate (Fig. 12 and 13), abrasive wear is the dominant wear mechanism in specimens equipped with surface composite layer.

Fig. 16 shows the surface profiles of wear tracks of BM and other FSPed specimens after testing under dry conditions. The wear track of the FSPed BM was the deepest and the most broad one, while the track of $100 \%$ MAX was the shallowest one because of its lowest friction coefficient. Contrary to the expectation that the specimen containing harder particles usually has a shallower wear track (50), the specimen with max phase particles showed the shallowest wear track. As mentioned above the layered structure of MAX phases can act as lubricant and result in lower wear rate. The composite consisting of these particles exhibits lubrication characteristics. 


\section{Conclusions}

This study explored fabrication and characterization of Al7075-T6 / $\mathrm{Al}_{2} \mathrm{O}_{3}$ / MAX phase hybrid surface nanocomposite by FSP at different hybrid ratios of reinforcements, and engaged with effects on mechanical and wear properties. Results showed that maximum tensile strength and hardness value were achieved for $\mathrm{Al}-100 \% \mathrm{Al}_{2} \mathrm{O}_{3}$ composite due to more grain refinement and effective dispersion of nanoparticles. The microhardness and tensile strength of the as-received alloy and optimum surface nanocomposite specimens were about $88 \mathrm{Hv}, 292.19 \mathrm{MPa}$ and $108 \mathrm{Hv}$ and $351.12 \mathrm{MPa}$, respectively. Surface nanocomposites revealed low friction coefficients and wear rates, which were significantly lower than those obtained for the substrate. Scanning electron microscopy tests revealed both adhesive and abrasive wear mechanisms on the surface of the wear test specimens.

\section{Declarations}

-Ethical Approval: All authors approve the ethical behavior.

-Consent to Participate: Not applicable.

-Consent to Publish: All authors consent to publish their research paper in The International Journal of Advanced Manufacturing Technology.

-Authors Contributions: All authors contributed equally.

-Funding: Not applicable.

-Competing Interests: Not applicable.

-Availability of data and materials: All data and materials are available.

\section{References}

[1] Totten, G. E., and MacKenzie, D. S. (2003) Handbook of aluminum: vol. 1: physical metallurgy and processes, CRC press.

[2] Heinz, A., Haszler, A., Keidel, C., Moldenhauer, S., Benedictus, R., and Miller, W. (2000) Recent development in aluminium alloys for aerospace applications. Materials Science and Engineering: A 280, 102-107.

[3] Williams, J. C., and Starke Jr, E. A. (2003) Progress in structural materials for aerospace systems. Acta Materialia 51, 5775-5799.

[4] Miracle, D. (2005) Metal matrix composites-from science to technological significance. Composites science and technology $65,2526-2540$. 
[5] Guo, J., Gougeon, P., and Chen, X.-G. (2012) Study on laser welding of AA1100-16 vol.\% B4C metalmatrix composites. Composites Part B: Engineering 43, 2400-2408.

[6] Ahmadifard, S., Kazemi, S., and Heidarpour, A. (2018) Production and characterization of A5083Al203-TiO2 hybrid surface nanocomposite by friction stir processing. Proceedings of the Institution of Mechanical Engineers, Part L: Journal of Materials: Design and Applications 232, 287-293.

[7] Hosseini, S., Ranjbar, K., Dehmolaei, R., and Amirani, A. (2015) Fabrication of Al5083 surface composites reinforced by CNTs and cerium oxide nano particles via friction stir processing. Journal of Alloys and Compounds 622, 725-733.

[8] Srinivasu, R., Rao, A. S., Reddy, G. M., and Rao, K. S. (2015) Friction stir surfacing of cast A356 aluminium-silicon alloy with boron carbide and molybdenum disulphide powders. Defence Technology $11,140-146$.

[9] Mahmoud, E. R., Takahashi, M., Shibayanagi, T., and Ikeuchi, K. (2010) Wear characteristics of surfacehybrid-MMCs layer fabricated on aluminum plate by friction stir processing. Wear 268, 1111-1121.

[10] Asl, A. M., and Khandani, S. (2013) Role of hybrid ratio in microstructural, mechanical and sliding wear properties of the Al5083/Graphitep/Al203p a surface hybrid nanocomposite fabricated via friction stir processing method. Materials Science and Engineering: A 559, 549-557.

[11] Dubourg, L., Hlawka, F., and Cornet, A. (2002) Surface and coatings technology.

[12] Choo, S.-H., Lee, S., and Kwon, S.-J. (1999) Effect of flux addition on the microstructure and hardness of TiC-reinforced ferrous surface composite layers fabricated by high-energy electron beam irradiation. Metallurgical and Materials Transactions A 30, 3131-3141.

[13] Znamirowski, Z., Pawlowski, L., Cichy, T., and Czarczynski, W. (2004) Low macroscopic field electron emission from surface of plasma sprayed and laser engraved TiO2, Al2O3+13TiO2 and Al2O3+40TiO2 coatings. Surface and coatings Technology 187, 37-46.

[14] Mishra, R. S., and Ma, Z. (2005) Friction stir welding and processing. Materials science and engineering: $R$ : reports $50,1-78$.

[15] Arora, H., Singh, H., and Dhindaw, B. (2012) Composite fabrication using friction stir processing-a review. The International Journal of Advanced Manufacturing Technology 61, 1043-1055.

[16] Gibson, B. T., Lammlein, D., Prater, T., Longhurst, W., Cox, C., Ballun, M., Dharmaraj, K., Cook, G., and Strauss, A. (2014) Friction stir welding: process, automation, and control. Journal of Manufacturing Processes 16, 56-73.

[17] Humphreys, F. J., Prangnell, P. B., and Priestner, R. (2001) Fine-grained alloys by thermomechanical processing. Current Opinion in Solid State and Materials Science 5, 15-21. 
[18] Bai, Y., He, X., Wang, R., Wang, S., and Kong, F. (2014) Effect of transition metal (M) and M-C slabs on equilibrium properties of Al-containing MAX carbides: An ab initio study. Computational materials science $91,28-37$.

[19] McNelley, T., Swaminathan, S., and Su, J. (2008) Recrystallization mechanisms during friction stir welding/processing of aluminum alloys. Scripta Materialia 58, 349-354.

[20] Shahi, A., Sohi, M. H., Ahmadkhaniha, D., and Ghambari, M. (2014) In situ formation of Al-Al $3 \mathrm{Ni}$ composites on commercially pure aluminium by friction stir processing. The International Journal of Advanced Manufacturing Technology 75, 1331-1337.

[21] Guru, P., Khan, F., Panigrahi, S., and Ram, G. J. (2015) Enhancing strength, ductility and machinability of a Al-Si cast alloy by friction stir processing. Journal of Manufacturing Processes 18, 67-74.

[22] Kheirkhah, S., Imani, M., Aliramezani, R., Zamani, M., and Kheilnejad, A. (2019) Microstructure, mechanical properties and corrosion resistance of Al6061/BN surface composite prepared by friction stir processing. Surface Topography: Metrology and Properties 7, 035002.

[23] Rao, A., Deshmukh, V., Prabhu, N., and Kashyap, B. (2016) Enhancing the machinability of hypereutectic Al-30Si alloy by friction stir processing. Journal of Manufacturing Processes 23, 130-134.

[24] Da Silva, J., Costa, J., Loureiro, A., and Ferreira, J. (2013) Fatigue behaviour of AA6082-T6 MIG welded butt joints improved by friction stir processing. Materials \& Design 51, 315-322.

[25] Sharma, S. R., Ma, Z., and Mishra, R. S. (2004) Effect of friction stir processing on fatigue behavior of A356 alloy. Scripta Materialia 51, 237-241.

[26] Mazaheri, Y., Karimzadeh, F., and Enayati, M. (2014) Tribological behavior of A356/Al 203 surface nanocomposite prepared by friction stir processing. Metallurgical and Materials Transactions A 45, 2250 2259.

[27] Hussain, G., Hashemi, R., Hashemi, H., and Al-Ghamdi, K. A. (2016) An experimental study on multipass friction stir processing of Al/TiN composite: some microstructural, mechanical, and wear characteristics. The International Journal of Advanced Manufacturing Technology 84, 533-546.

[28] Poon, B., Ponson, L., Zhao, J., and Ravichandran, G. (2011) Damage accumulation and hysteretic behavior of MAX phase materials. Journal of the Mechanics and Physics of Solids 59, 2238-2257.

[29] Heidarpour, A., Shahin, N., and Kazemi, S. (2017) A novel approach to in situ synthesis of WC-Al203 composite by high energy reactive milling. International Journal of Refractory Metals and Hard Materials $64,1-6$.

[30] Zhou, A., Wang, C.-A., and Hunag, Y. (2003) Synthesis and mechanical properties of Ti 3 AlC 2 by spark plasma sintering. Journal of materials science 38, 3111-3115. 
[31] Tzenov, N. V., and Barsoum, M. W. (2000) Synthesis and characterization of Ti3AlC2. Journal of the American Ceramic Society 83, 825-832.

[32] Yeh, C., Kuo, C., and Chu, Y. (2010) Formation of Ti3AlC2/Al2O3 and Ti2AlC/Al2O3 composites by combustion synthesis in Ti-Al-C-TiO2 systems. Journal of Alloys and Compounds 494, 132-136.

[33] Yeh, C., and Shen, Y. (2009) Effects of using Al4C3 as a reactant on formation of Ti3AlC2 by combustion synthesis in SHS mode. Journal of alloys and compounds 473, 408-413.

[34] Shahin, N., Kazemi, S., and Heidarpour, A. (2016) Mechanochemical synthesis mechanism of Ti3AlC2 MAX phase from elemental powders of Ti, Al and C. Advanced Powder Technology 27, 1775-1780.

[35] Jin, S., Liang, B., Li, J.-F., and Ren, L. (2007) Effect of Al addition on phase purity of Ti3Si (Al) C2 synthesized by mechanical alloying. Journal of materials processing technology $182,445-449$.

[36] Liang, B., Han, X., Zou, Q., Zhao, Y., and Wang, M. (2009) TiC/Ti3SiC2 composite prepared by mechanical alloying. International Journal of Refractory Metals and Hard Materials 27, 664-666.

[37] Khodabakhshi, F., Simchi, A., Kokabi, A., Nosko, M., Simanĉik, F., and Švec, P. (2014) Microstructure and texture development during friction stir processing of $\mathrm{Al}-\mathrm{Mg}$ alloy sheets with $\mathrm{TiO} 2$ nanoparticles. Materials Science and Engineering: A 605, 108-118.

[38] Du, Z., Tan, M. J., Guo, J. F., Bi, G., and Wei, J. (2016) Fabrication of a new Al-Al203-CNTs composite using friction stir processing (FSP). Materials Science and Engineering: A 667, 125-131.

[39] Chabok, A., and Dehghani, K. (2010) Formation of nanograin in IF steels by friction stir processing. Materials Science and Engineering: A 528, 309-313.

[40] Kou, S. (2003) Welding metallurgy. New Jersey, USA, 431-446.

[41] Gholami, S., Emadoddin, E., Tajally, M., and Borhani, E. (2015) Friction stir processing of 7075 Al alloy and subsequent aging treatment. Transactions of Nonferrous Metals Society of China 25, 2847-2855.

[42] Mishra, R. S., McFadden, S., Mara, N., Mukherjee, A., and Mahoney, M. W. (1999) High strain rate superplasticity in a friction stir processed $7075 \mathrm{Al}$ alloy.

[43] Devaraju, A., Kumar, A., and Kotiveerachari, B. (2013) Influence of addition of Grp/Al203p with SiCp on wear properties of aluminum alloy 6061-T6 hybrid composites via friction stir processing.

Transactions of Nonferrous Metals Society of China 23, 1275-1280.

[44] Tjong, S., Lau, K., and Wu, S. (1999) Wear of Al-based hybrid composites containing BN and SiC particulates. Metallurgical And Materials Transactions 30, 2551.

[45] Hosseini, N., Karimzadeh, F., Abbasi, M., and Enayati, M. (2010) Tribological properties of Al6061Al2O3 nanocomposite prepared by milling and hot pressing. Materials \& Design 31, 4777-4785. 
[46] Barsoum, M. W. (2013) MAX phases: properties of machinable ternary carbides and nitrides, John Wiley \& Sons.

[47] Huq, M., and Celis, J.-P. (1997) Reproducibility of friction and wear results in ball-on-disc unidirectional sliding tests of TiN-alumina pairings. Wear 212, 151-159.

[48] Wan, D., Hu, C., Bao, Y., and Zhou, Y. (2007) Effect of SiC particles on the friction and wear behavior of Ti3Si (Al) C2-based composites. Wear 262, 826-832.

[49] Schmidt, H. N. B., Dickerson, T., and Hattel, J. H. (2006) Material flow in butt friction stir welds in AA2024-T3. Acta Materialia 54, 1199-1209.

[50] Ahmadifard, S., Kazemi, S., and Momeni, A. (2018) A356/TiO 2 Nanocomposite Fabricated by Friction Stir Processing: Microstructure, Mechanical Properties and Tribologic Behavior. Jom 70, 26262635.

\section{Tables}

Table 1: Chemical composition of aluminum 7075-T6 used in this study (in wt. \%)

\begin{tabular}{|llllllll|}
\hline Element & $\mathrm{Al}$ & $\mathrm{Mg}$ & $\mathrm{Si}$ & $\mathrm{Fe}$ & $\mathrm{Cu}$ & $\mathrm{Zn}$ & $\mathrm{Cr}$ \\
\hline Composition (Wt.\%) & Bal. & 2.45 & 0.39 & 0.51 & 1.65 & 5.71 & 0.23 \\
\hline
\end{tabular}

Table 2: Average grain size values measured from optical micrographs

\begin{tabular}{|llllll|}
\hline Material and process & $\begin{array}{l}\mathrm{As} \\
\text { received }\end{array}$ & $\begin{array}{l}\mathrm{FSPed} \\
\mathrm{Al}\end{array}$ & $\begin{array}{l}\mathrm{Al}-100 \% \\
\mathrm{Al}_{2} \mathrm{O}_{3}\end{array}$ & $\begin{array}{l}\mathrm{Al}-50 \% \mathrm{Al}_{2} \mathrm{O}_{3}+50 \% \\
\mathrm{MAX}\end{array}$ & $\begin{array}{l}\mathrm{Al}-100 \% \\
\mathrm{MAX}\end{array}$ \\
\hline $\begin{array}{l}\text { Average grain size } \\
(\mu \mathrm{m})\end{array}$ & $16 \pm 0.5$ & $7.6 \pm 0.5$ & $3.3 \pm 0.5$ & $4.6 \pm 0.5$ & $5.4 \pm 0.5$ \\
\hline
\end{tabular}

Table 3: Tensile properties of the base metal and FSPed specimens 


\begin{tabular}{|c|c|c|c|c|c|c|c|}
\hline $\begin{array}{l}\text { Microhardness } \\
(\mathrm{Hv})\end{array}$ & $\begin{array}{l}\text { Depth } \\
\text { of } \\
\text { wear } \\
\text { trach } \\
(\mu \mathrm{m})\end{array}$ & $\begin{array}{l}\text { Weight } \\
\text { Loss } \\
\text { (mg) }\end{array}$ & $\begin{array}{l}\text { Friction } \\
\text { Coefficient }\end{array}$ & $\begin{array}{l}\text { Ultimate } \\
\text { Tensile } \\
\text { Strength } \\
\text { (MPa) }\end{array}$ & $\begin{array}{l}\text { Total } \\
\text { elongation } \\
(\%)\end{array}$ & $\begin{array}{l}\text { surface } \\
\text { roughness } \\
(\mathrm{nm})\end{array}$ & Sample \\
\hline 88 & -551.1 & 0.055 & 0.663 & 292.19 & 0.332 & - & BM \\
\hline 71 & -655.5 & 0.067 & 0.878 & 243.21 & 0.244 & -- & $\begin{array}{l}\text { FSPed } \\
\text { BM }\end{array}$ \\
\hline 94 & -475.3 & 0.034 & 0.192 & 327.86 & 0.304 & 252.9 & $\begin{array}{l}100 \% \\
\text { MAX }\end{array}$ \\
\hline 108 & -523.6 & 0.043 & 0.421 & 351.12 & 0.251 & 156.8 & $\begin{array}{l}100 \% \\
\mathrm{Al}_{2} \mathrm{O}_{3}\end{array}$ \\
\hline 101 & -491.2 & 0.041 & 0.324 & 339.39 & 0.274 & 218.1 & $\begin{array}{l}50 \% \\
\mathrm{Al}_{2} \mathrm{O}_{3} \\
50 \% \\
\text { MAX }\end{array}$ \\
\hline
\end{tabular}

\section{Figures}

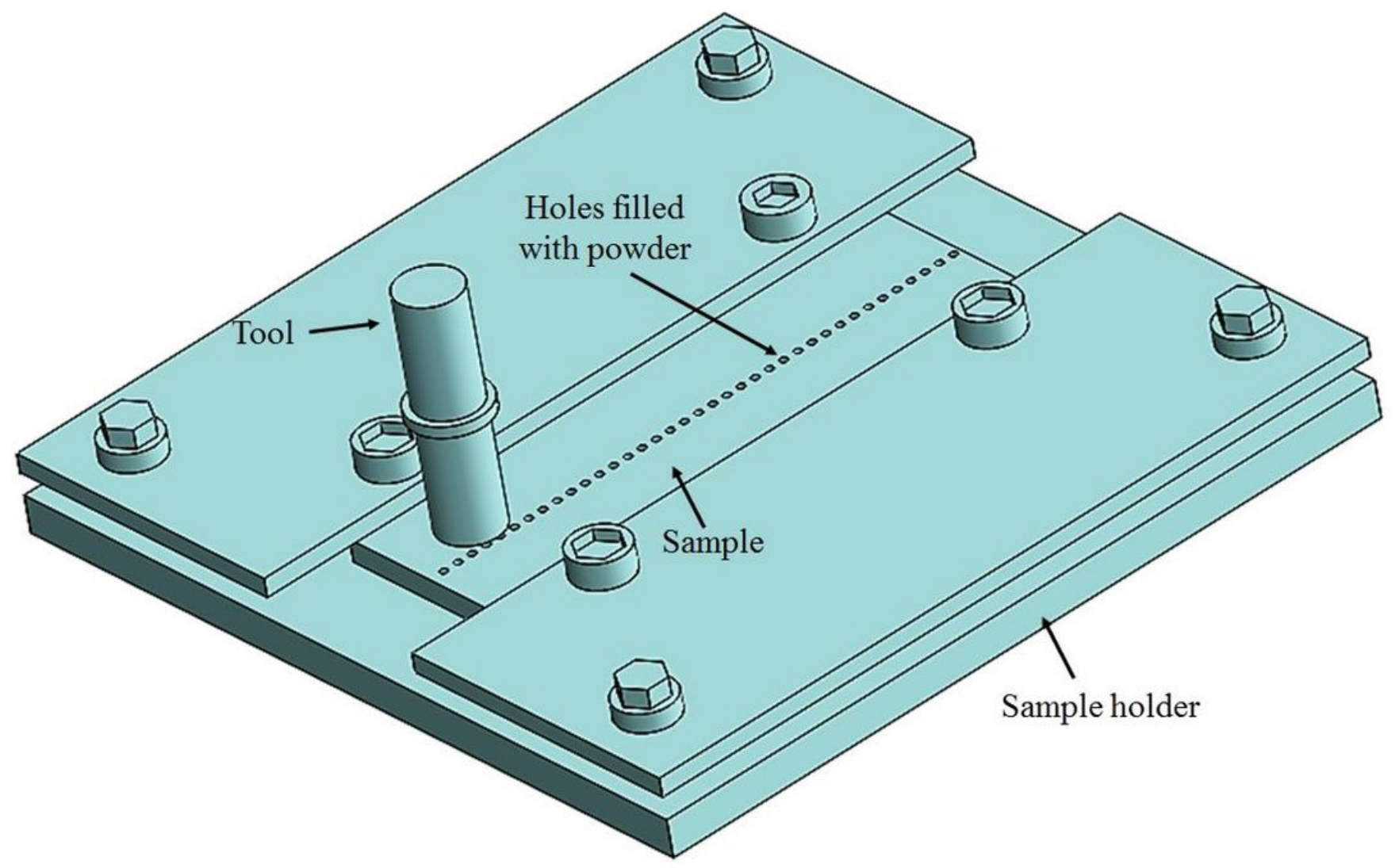


Schematic of work piece used in this study.
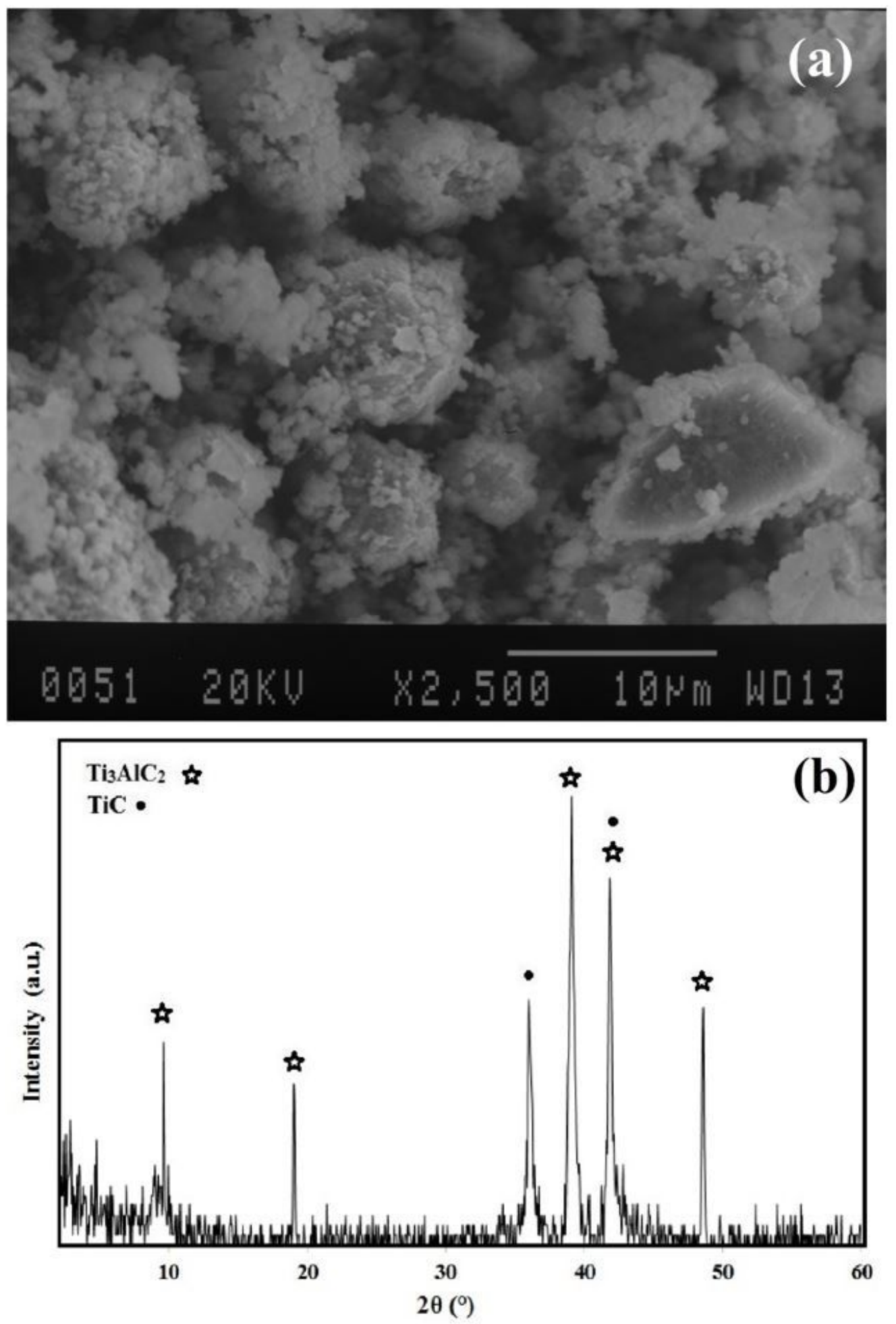

Figure 2

(a) SEM micrograph and (b) XRD spectrum of the Ti3AIC2 MAX powder used in this investigation. 


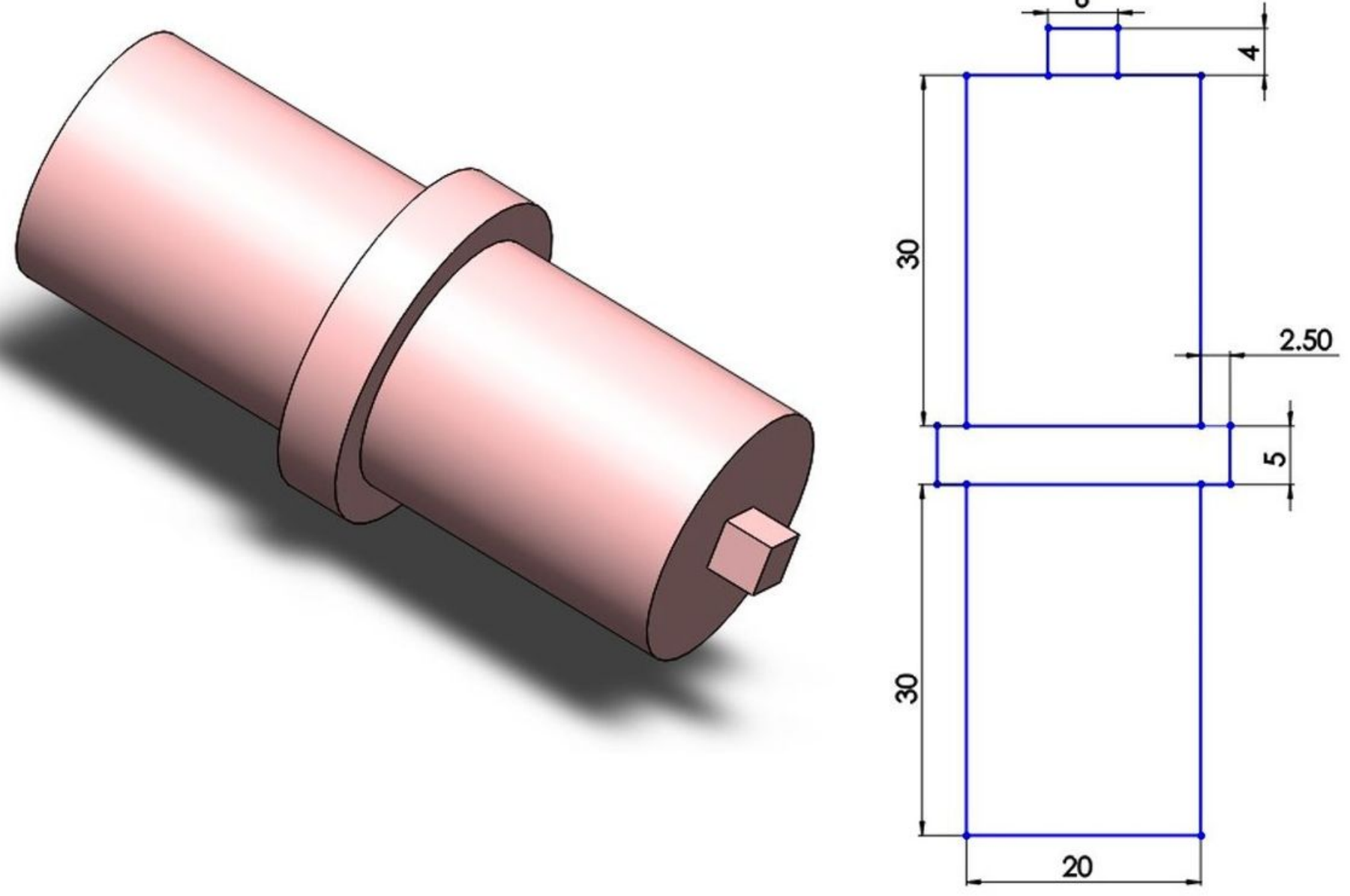

Figure 3

Schematic of the threaded tool and its dimensions (dimensions are in $\mathrm{mm}$ ). 
(a)

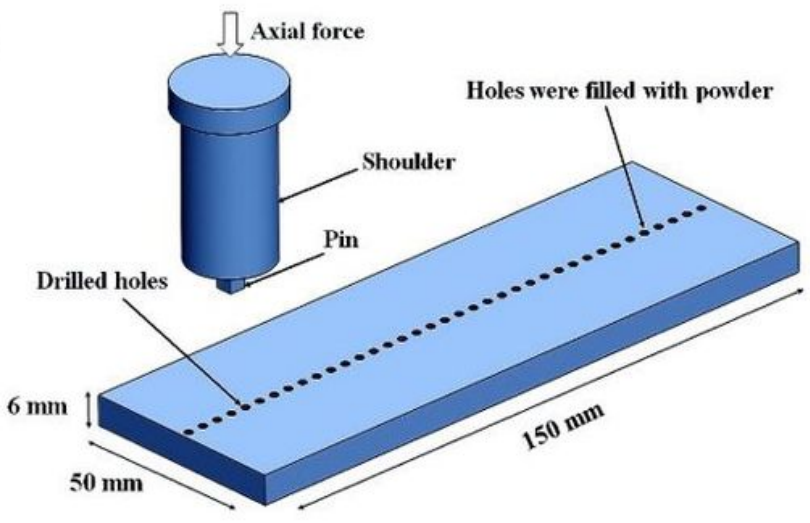

(b)

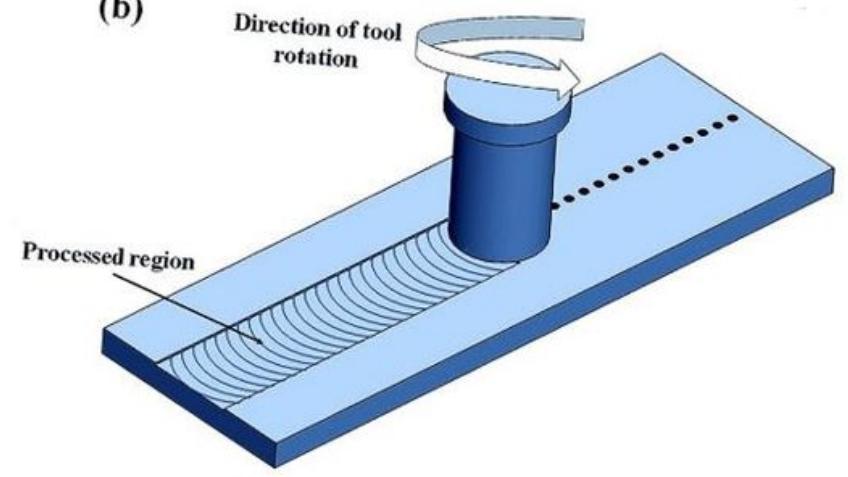

(c)
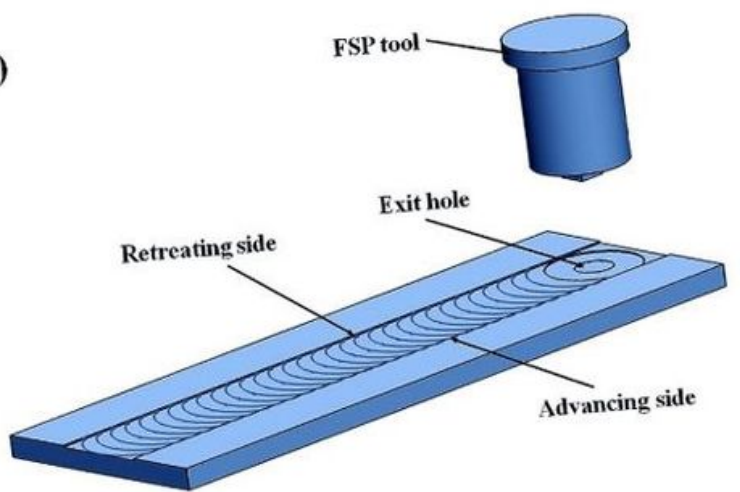

\section{Figure 4}

Schematic process of composite fabrication by FSP method.

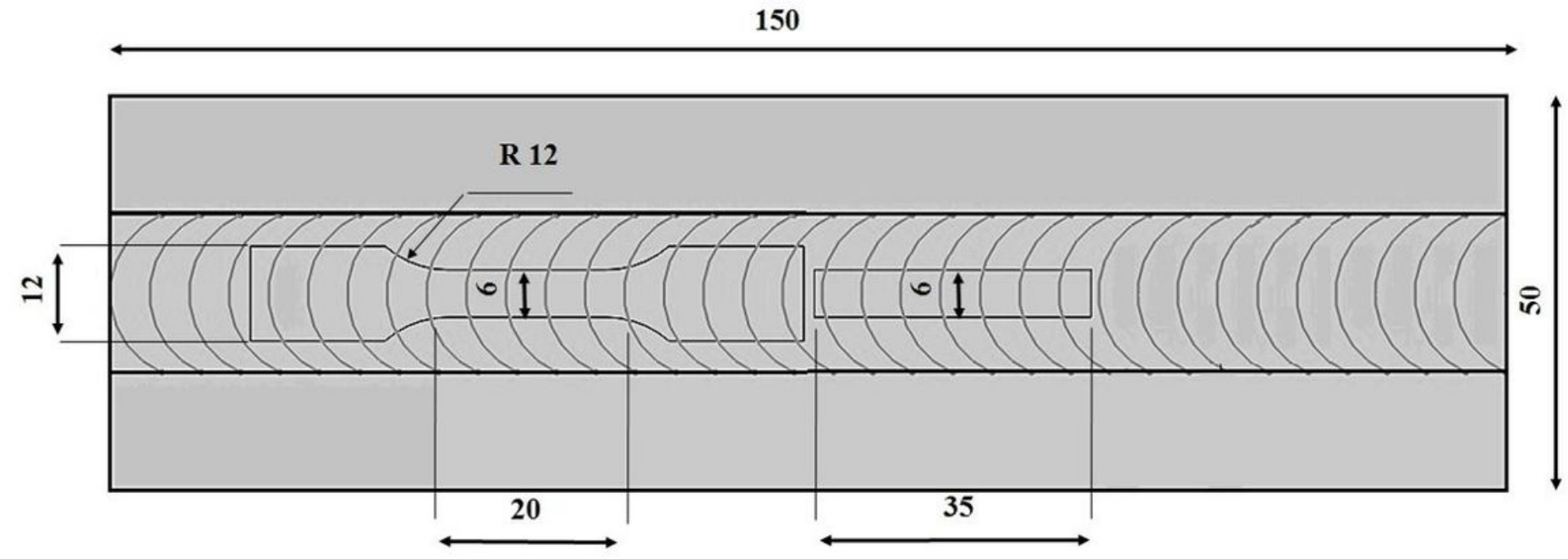

Figure 5

Schematic image of tensile and wear test samples (dimensions are in $\mathrm{mm}$ ). 

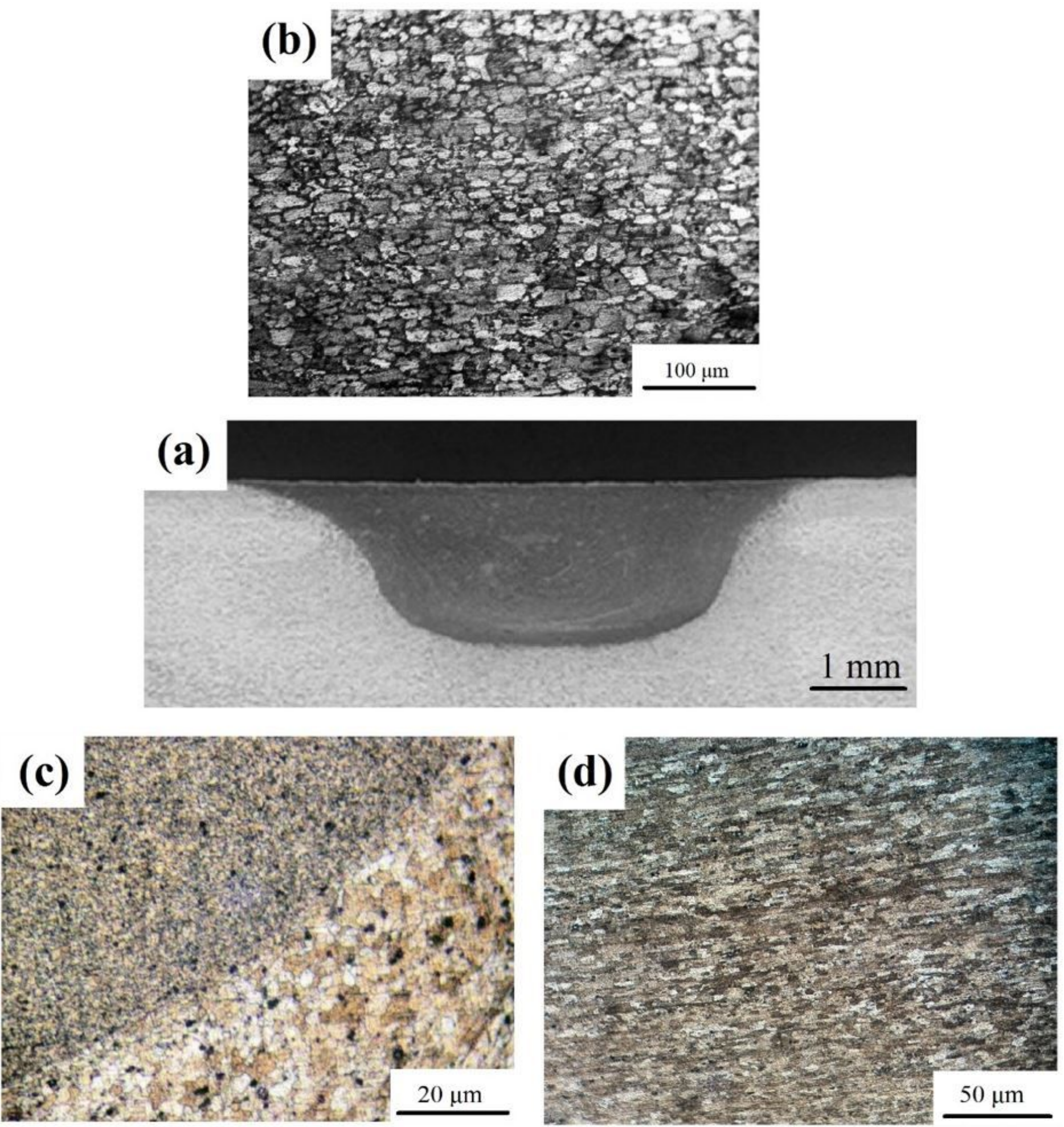

\section{Figure 6}

Optical micrograph of a) different zones of FSPed Al alloy, b) base metal, c) FSP boundary and d) SZ after three passes FSP. 

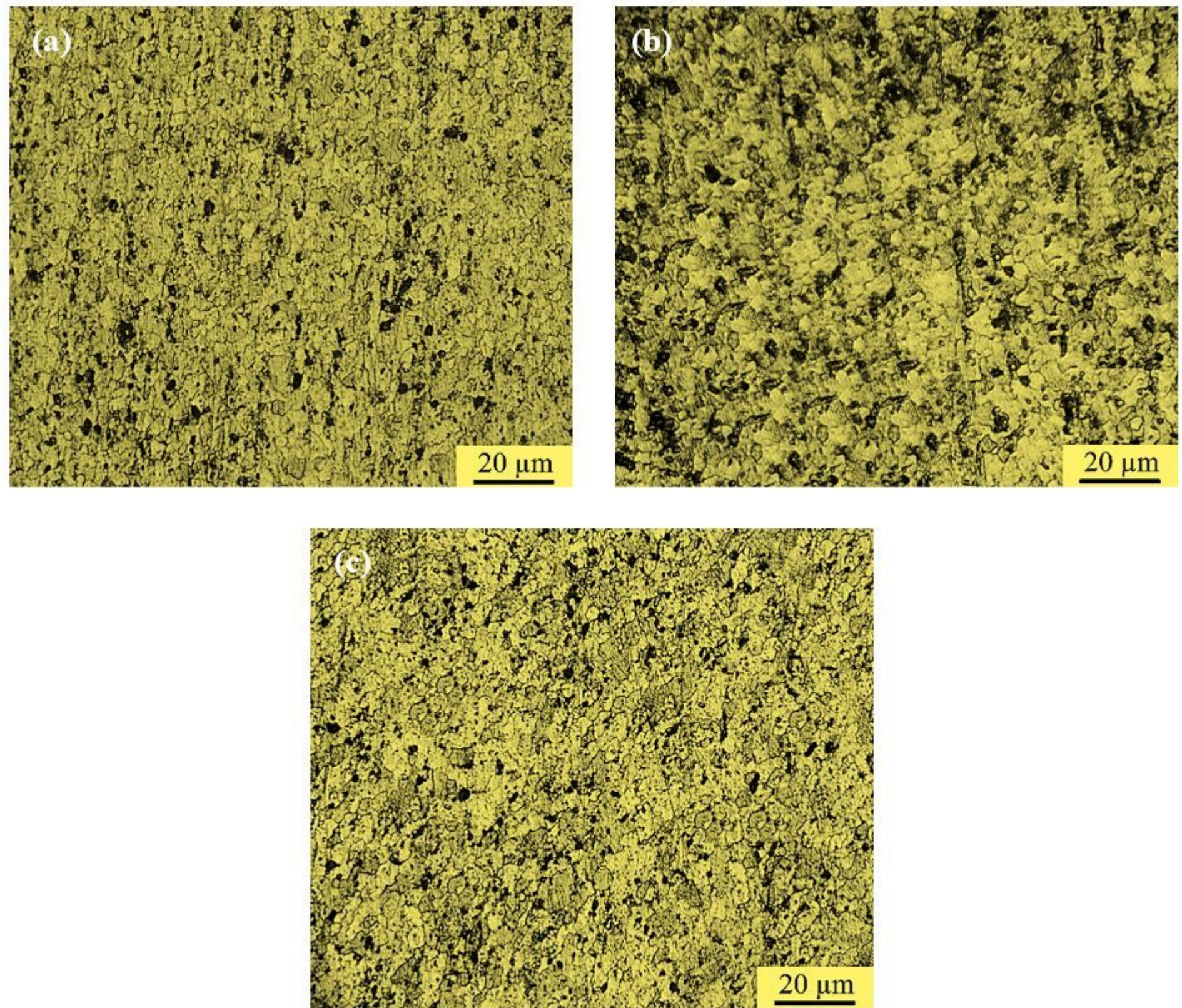

\section{Figure 7}

Optical micrographs of fabricated composites produced by (a) $100 \%$ Al203, (b) $100 \%$ MAX, (c) $50 \%$ Al2O3 + $50 \%$ MAX. 

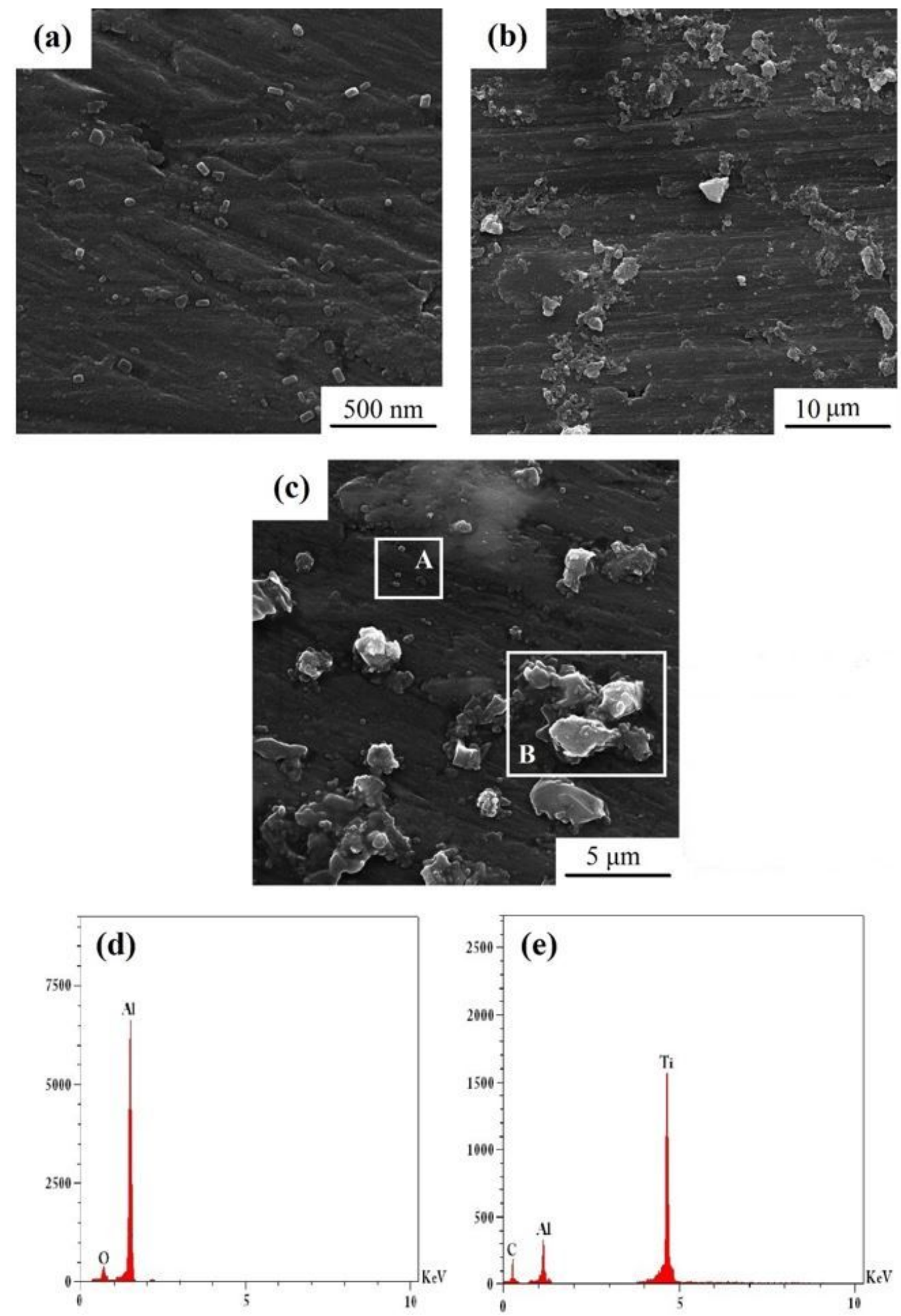

Figure 8

FESEM micrographs of fabricated composites produced by (a) $100 \%$ Al203, (b) $100 \%$ MAX, (c) $50 \%$ Al2O3 + 50\% MAX, (d) EDS results of the particles in A area and (e) EDS results of the particles in B area. 


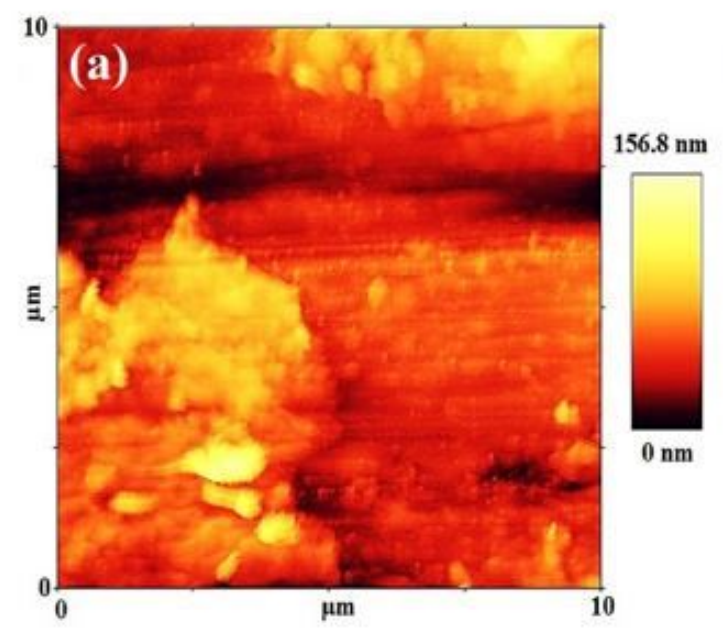

(b)
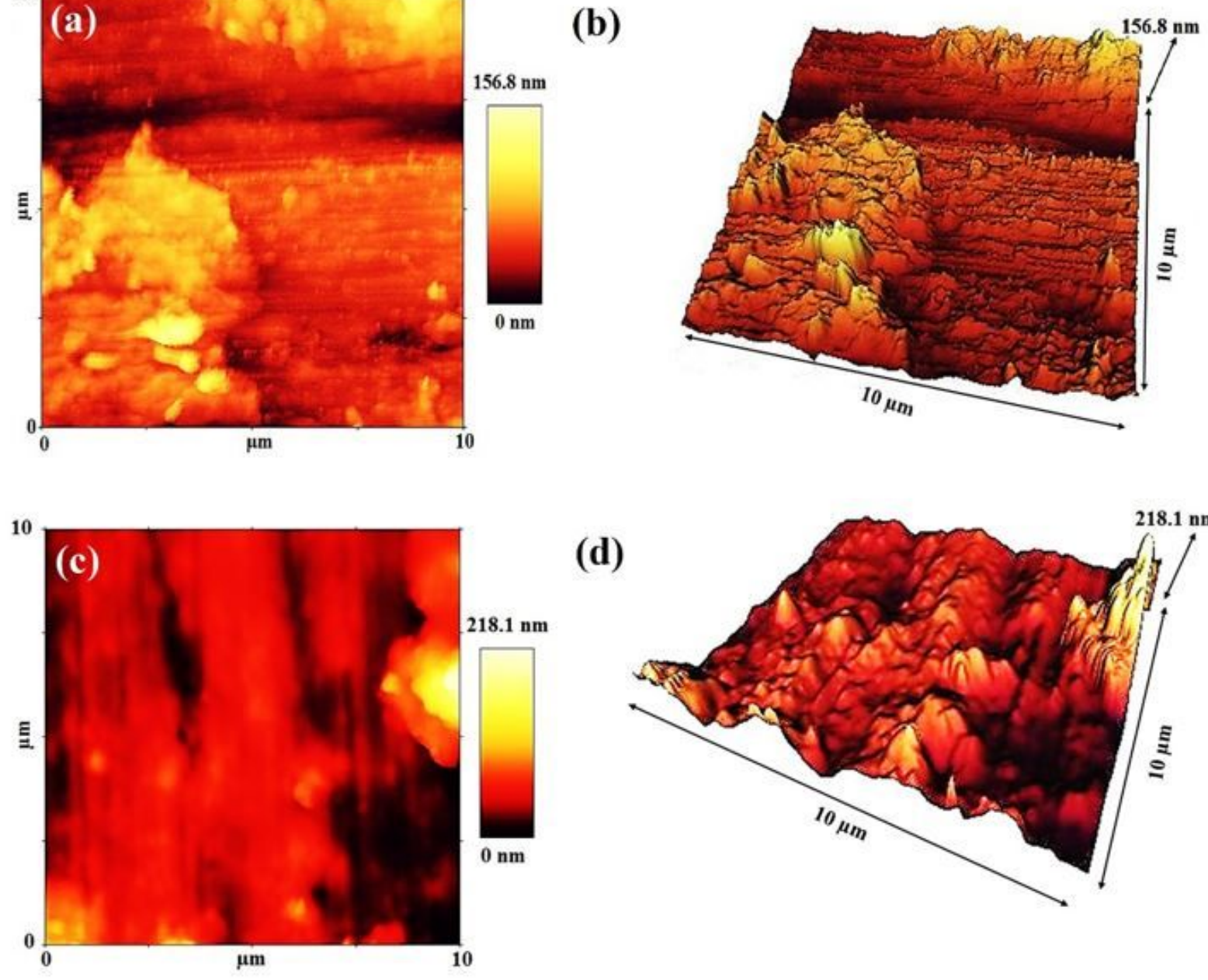

(d)
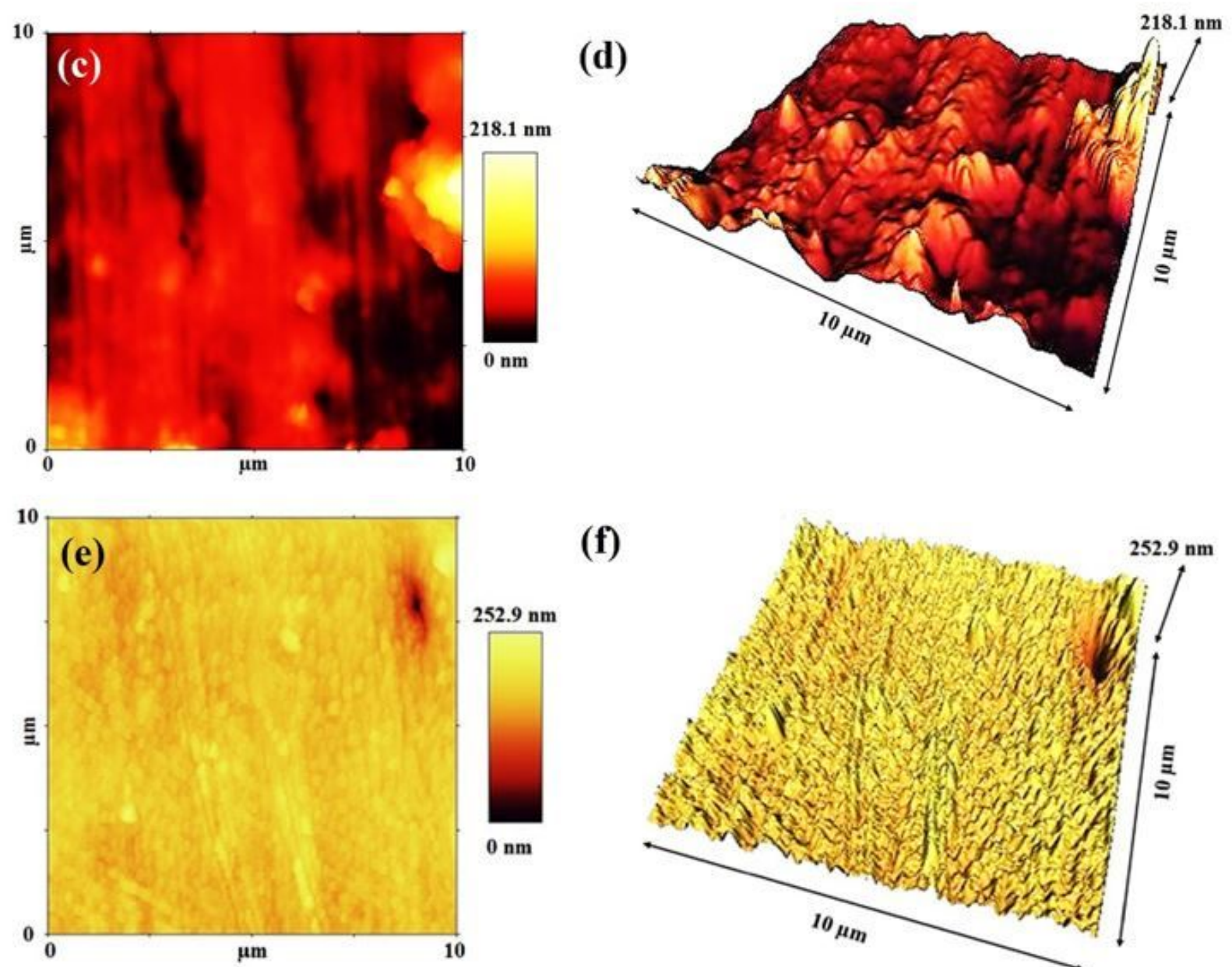

(f)

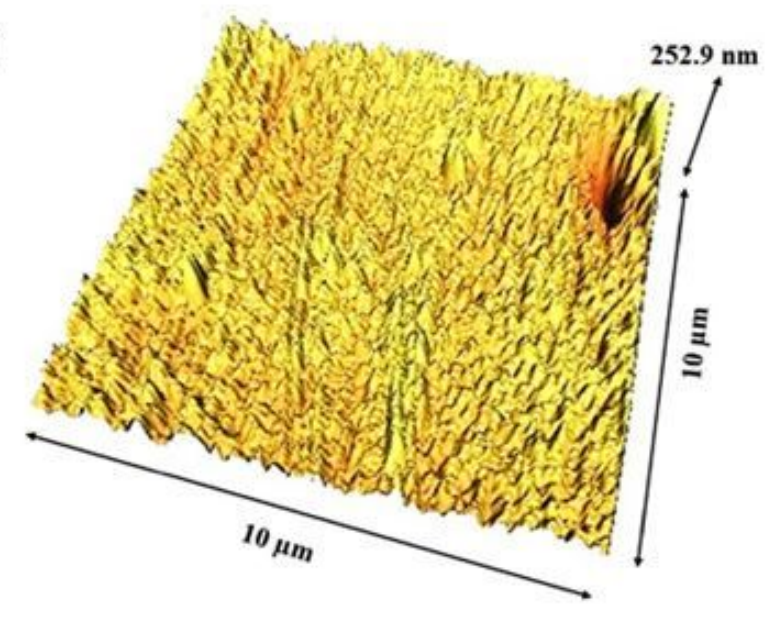

Figure 9

AFM micrographs from the fabricated composites in the SZ: a) 2D image reinforced by Al2O3 b) 3D image reinforced by Al2O3, (c) 2D image reinforced by $50 \%$ Al2O3 + $50 \%$ MAX, and (d) 3D image reinforced by $50 \%$ Al2O3 + $50 \%$ MAX, (e) 2D image reinforced by MAX, (f) 3D image reinforced by MAX. 


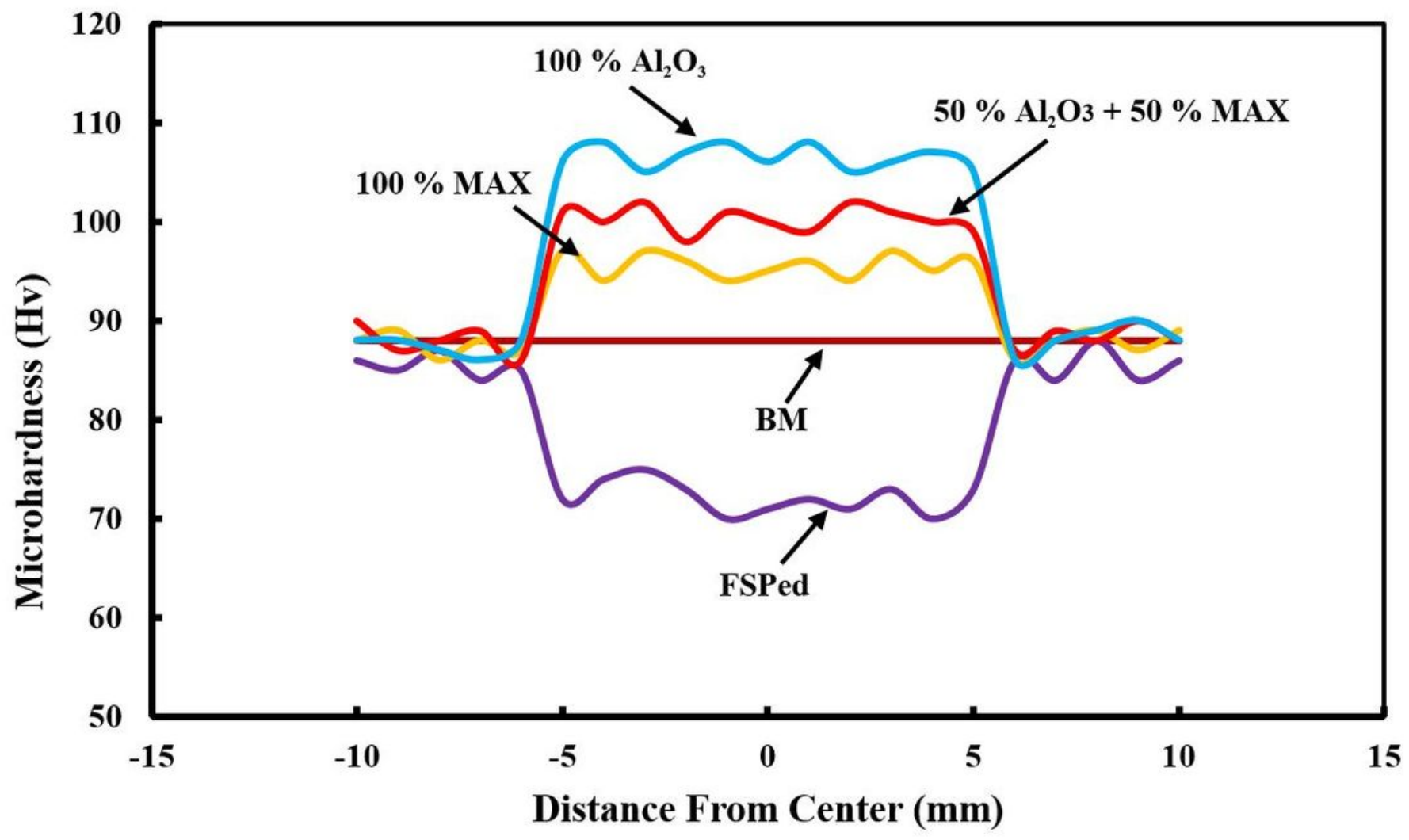

Figure 10

Microhardness profiles of the composites along the thickness cross section for different states.

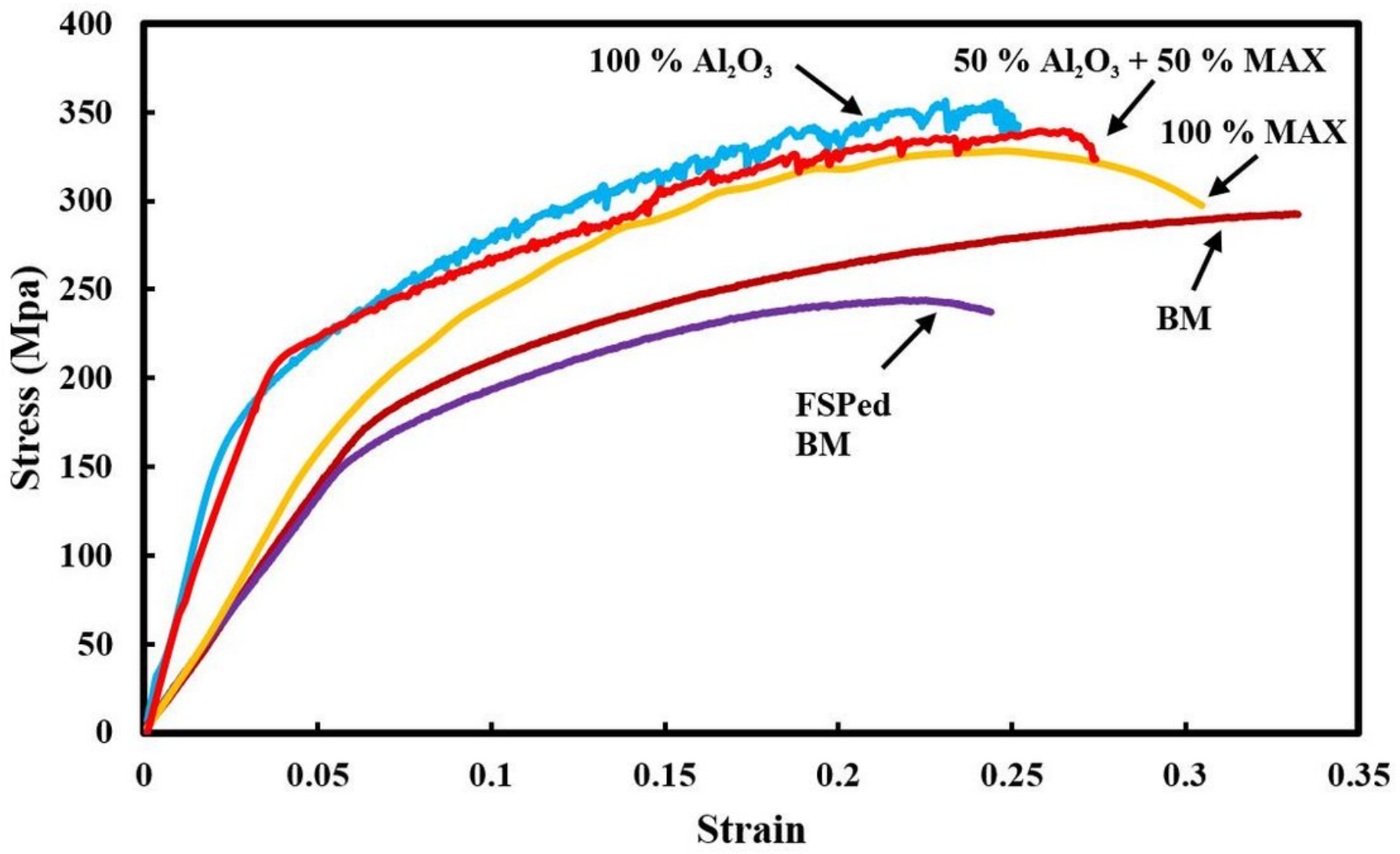


Figure 11

Stress-strain curves for as-received alloy and FSPed specimens.

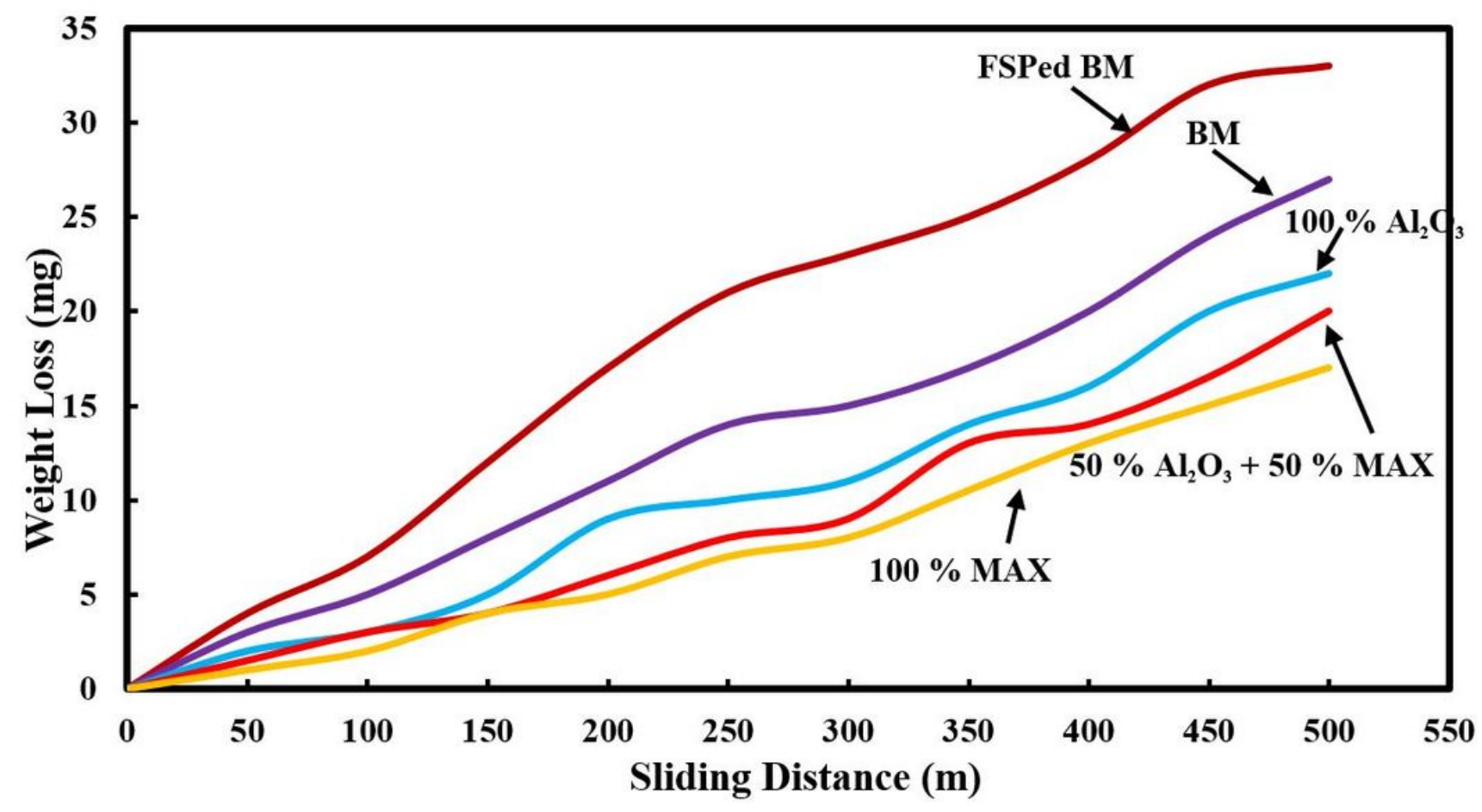

Figure 12

Variations in weight loss as a function of sliding distance for as-received alloy and FSPed specimens.

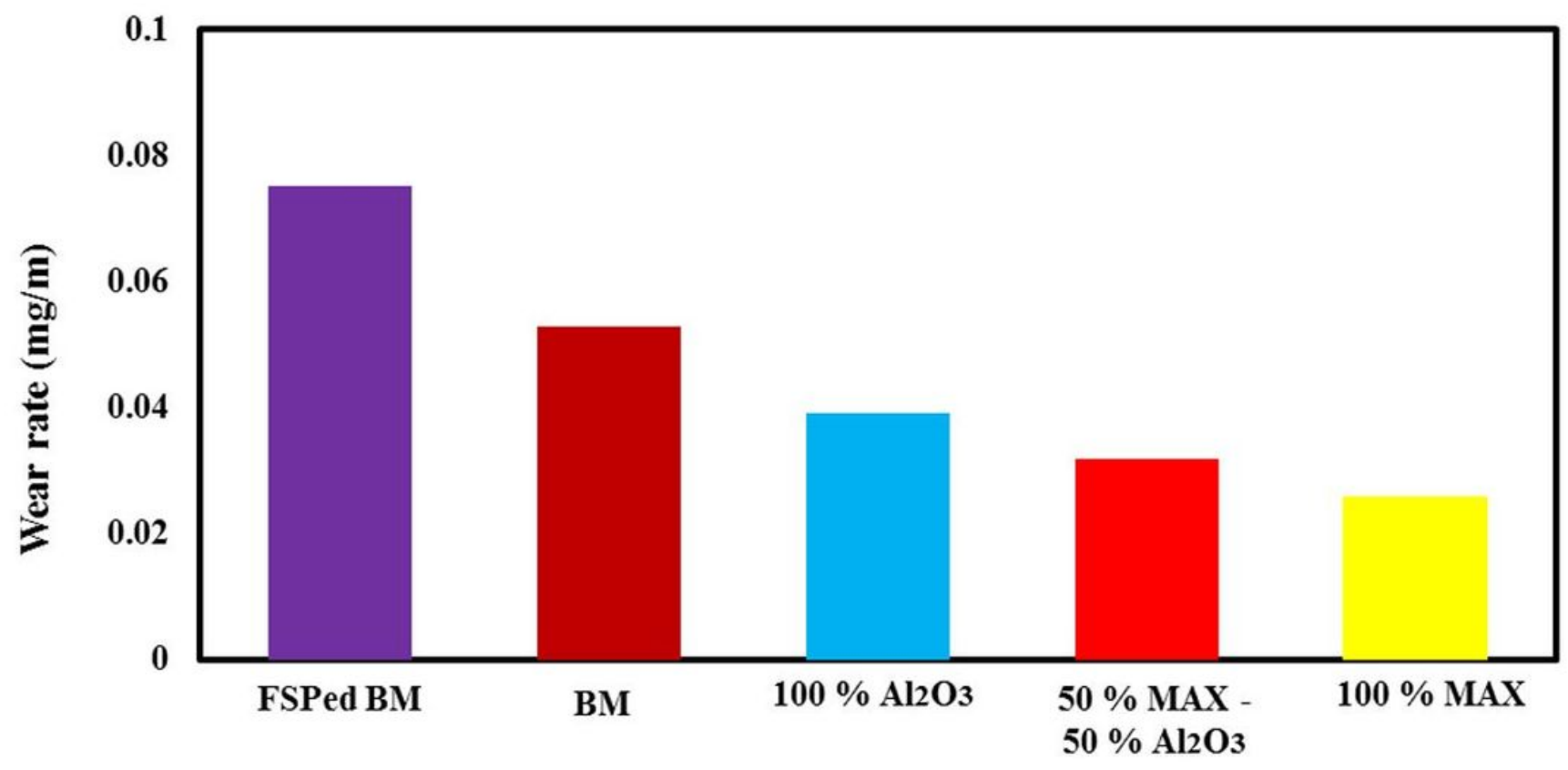

Samples

Figure 13 
Variations in wear rate as a function of sliding distance for as-received alloy and FSPed specimens.

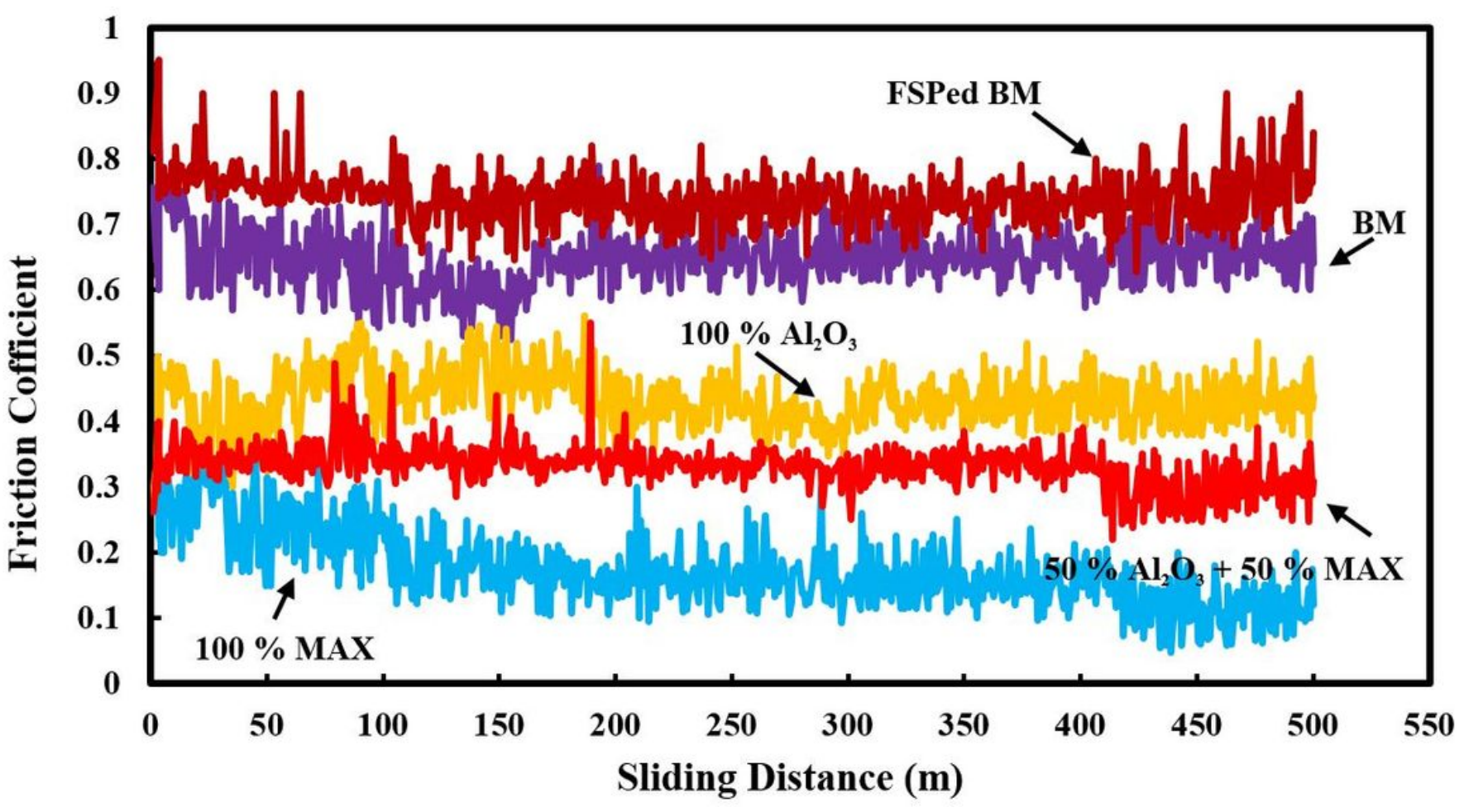

Figure 14

Variation of the friction coefficient with sliding distance of $500 \mathrm{~m}$ for as-received alloy and FSPed specimens. 

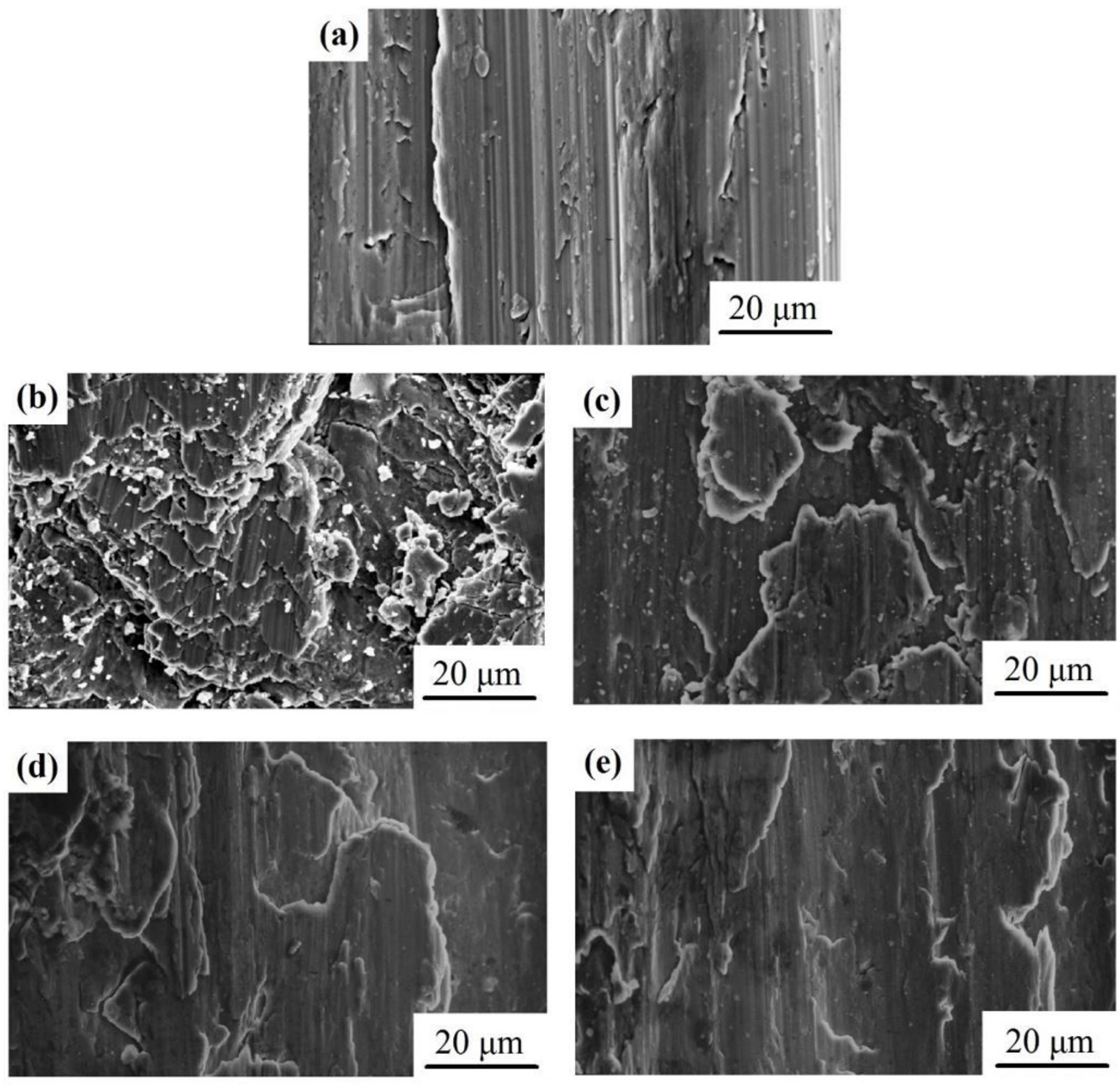

\section{Figure 15}

SEM microgragh of worn surfaces of (a) base metal, (b) FSPed base metal, (c) FSPed reinforced by 100 $\%$ Al203, (d) FSPed reinforced by $50 \%$ Al2O3 + $50 \%$ MAX and (e) FSPed reinforced by $100 \%$ MAX. 


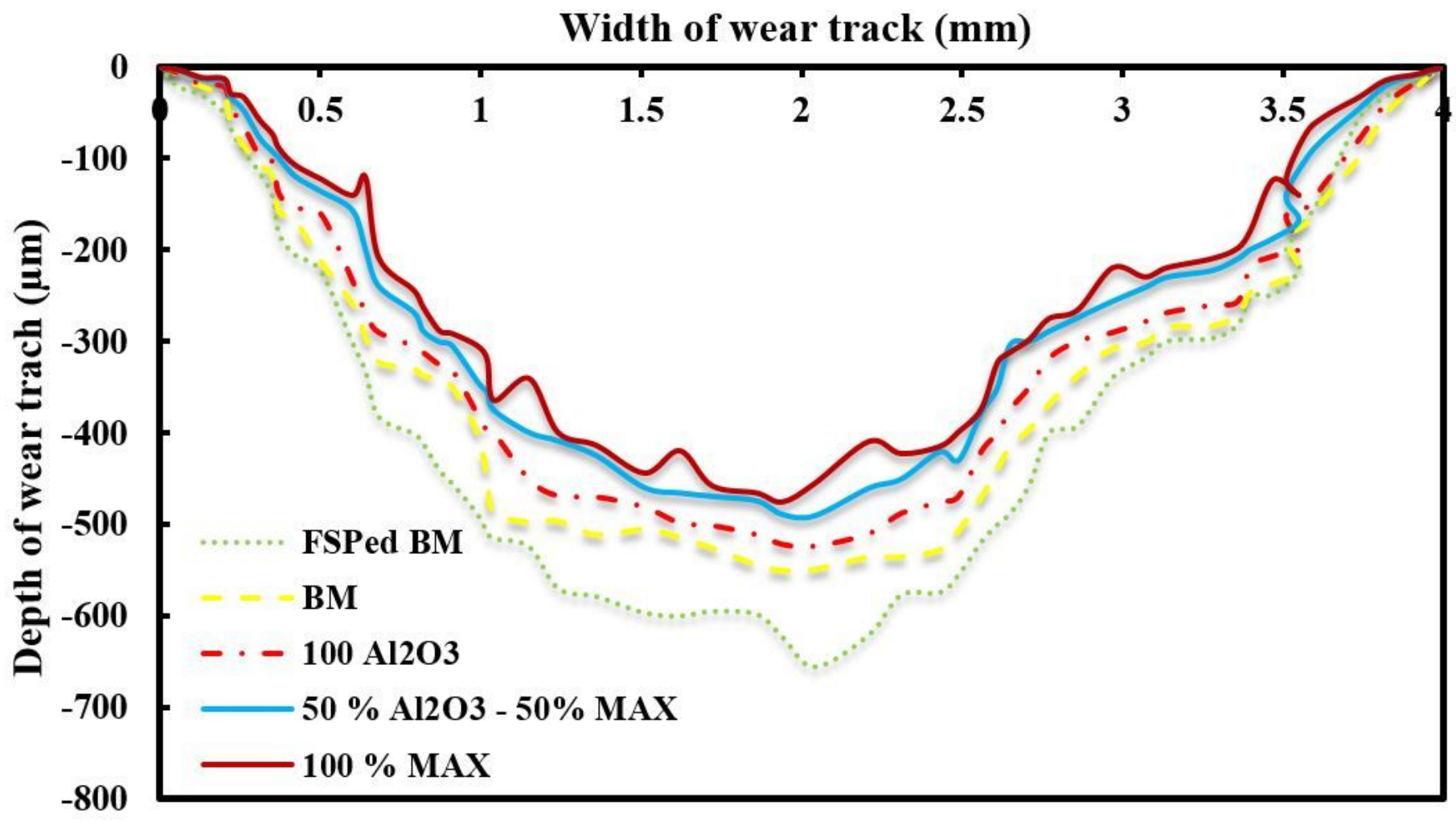

Figure 16

The surface profiles of the wear tracks for as-received alloy and FSPed specimens. 